Article

\title{
Promoting Interpersonal Relationships through Elbow Tag, a Traditional Sporting Game. A Multidimensional Approach
}

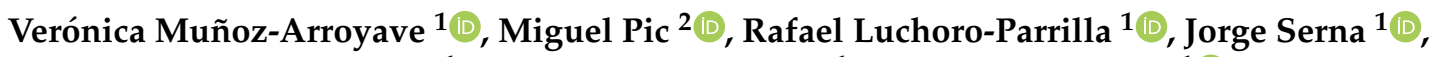 \\ Cristòfol Salas-Santandreu ${ }^{1}$, Sabrine Damian-Silva ${ }^{1}$, Leonardo Machado ${ }^{1} \mathbb{C}^{\circ}$, Rosa Rodríguez-Arregi ${ }^{1}{ }^{1}$, \\ Queralt Prat ${ }^{1} \mathbb{C}$, Conxita Duran-Delgado ${ }^{1}(\mathbb{B})$ and Pere Lavega-Burgués $1, * \mathbb{B}$
}

1 Motor Action Research Group (GIAM), INDEST, Institut Nacional d'Educació Física de Catalunya (INEFC), Universitat de Lleida (UdL), 25003 Lleida, Spain; vmunoz@gencat.cat (V.M.-A.);

lucho.parris@gmail.com (R.L.-P.); jserna@gencat.cat (J.S.); csalas@inefc.es (C.S.-S.); sabrinedamian@hotmail.com (S.D.-S.); leonardoed.fisica@hotmail.com (L.M.); rrodriguez@inefc.es (R.R.-A.); qprat@inefc.es (Q.P.); dconxa@yahoo.es (C.D.-D.)

2 Motor Action Research Group (GIAM), Institute of Sport, Tourism, and Service, South Ural State University, 454080 Chelyabinsk, Russia; pic.aguilar.90@ull.edu.es

* Correspondence: plavega@inefc.es

check for updates

Citation: Muñoz-Arroyave, V.; Pic, M.; Luchoro-Parrilla, R.; Serna, J.; Salas-Santandreu, C.; Damian-Silva, S.; Machado, L.; Rodríguez-Arregi, R.; Prat, Q.; Duran-Delgado, C.; et al.

Promoting Interpersonal

Relationships through Elbow Tag, a

Traditional Sporting Game. A

Multidimensional Approach.

Sustainability 2021, 13, 7887.

https://doi.org/10.3390/su13147887

Academic Editor: Jesús-Nicasio García-Sánchez

Received: 11 June 2021

Accepted: 9 July 2021

Published: 14 July 2021

Publisher's Note: MDPI stays neutral with regard to jurisdictional claims in published maps and institutional affiliations.

Copyright: (c) 2021 by the authors. Licensee MDPI, Basel, Switzerland. This article is an open access article distributed under the terms and conditions of the Creative Commons Attribution (CC BY) license (https:// creativecommons.org/licenses/by/ $4.0 /)$

\begin{abstract}
The aim of this research was to study from a multidimensional point of view (decisional, relational and energetic) the interpersonal relationships established by girls and boys in the traditional sport game of Elbow Tag. Scientific evidence has shown that Traditional Sport Games (TSG) trigger different effects on male and female genders in relation to emotional experiences, decision-making, conflicts and motor relationships. Despite the fact that these dimensions are intertwined, there are hardly any studies that interpret motor behaviors holistically, i.e., taking a multidimensional $\left(360^{\circ}\right)$ view of these dimensions. For this study, a quasi-experimental design was used and a type III design was applied, inspired by the observational methodology N/P/M. A total of 147 university students participated $(M=19.6, \mathrm{SD}=2.3)$ : 47 girls $(31.97 \%)$ and 100 boys $(68.02 \%)$. A mixed 'ad hoc' registration system was designed with acceptable margins of data quality. Cross-tabulations, classification trees and T-patterns analysis were applied. The results indicated that social interactions between girls and boys in a mixed group were unequal. This difference was mainly due to decisionmaking (sub-role variable), which has much greater predictive power than the energetic variables (MV and steps).
\end{abstract}

Keywords: intangible cultural heritage; motor praxiology; motor interaction; paradoxical game; motor action

\section{Introduction}

International institutions such as UNICEF [1] and UNESCO [2] identify the promotion of gender equality as one of the main challenges of today's society. UNICEF [1] proposes to activate a quality education system, which does not discriminate and offers equal opportunities for girls and boys to develop their talents and, consequently, have an impact on other areas of life (e.g., social, economic, etc.).

In the same line and with regards to the field of Physical Education and Sport, the so-called Kazan Plan was agreed to during the Sixth International Conference of Ministers and Senior Officers responsible for Physical Education and Sport (MINEPS VI). This agreement in Kazan (13-15 July 2017) establishes the strengthening of gender equality and the empowerment of girls and women through sport as one of the main priorities of the education system.

This project finds its scope for action and meaning in the major international challenges around the sustainable development goals set out in the 2030 agenda. On 25 September 2015, 193 countries committed to the 17 United Nations Sustainable Development Goals (SDGs) and their fulfilment by 2030. 
Thus, in European Agenda 2030 for sustainable development, achieving gender equality and empowerment of all girls and women is highlighted as a specific and cross-cutting objective. In this regard, European governments plan to make progress against genderbased violence, equal pay, equal treatment and equal opportunities between women and men, through the legislative and judicial powers.

However, physical education does not always promote gender equality and opportunities between girls and boys. Physical Education still continues to promote androcentric patterns [3-6].

Gender stereotypes associate females with sensitivity in human relations, empathy, interpersonal skills, ease of expressing emotions, and expressive and cooperative motor practices from an early age $[5,7,8]$. On the other hand, the male stereotype is oriented towards independence, competitiveness, strength and efficiency, towards motor practices of cooperation and opposition, especially in situations where there is competitive confrontation with the opponent [5,9-12]. This stereotype is present in the perceptions of girls and boys from a very early age. The study by $[3,13]$ shows that between the ages of 8 and 10 years it is already manifested in the perceptions of girls and boys from a very early age.

Therefore, it is clear that the promotion of gender equality is one of the great challenges of the present day [14], as it is necessary to continue working to transcend these models of masculinity and femininity in favor of a non-sexist Physical Education. To this end, it is necessary to equip teachers at all levels of education with the resources and skills necessary to develop competencies that enable girls and boys to learn in an equal educational environment [15].

In order to promote physical education with such equal opportunities for girls and boys, teachers have a wide variety of pedagogical resources at their disposal. Among them, the traditional sports game (TSG) [16] is often forgotten and undervalued in comparison to traditional sports. However, there is little scientific evidence that confirms the significant contribution of TSG to education in such necessary values as respect, equality, diversity and mutual support [17], which lead to gender equality.

According to the science of motor action, every TSG has an internal logic (IL) or identity card that guides the protagonists towards experiencing different types of motor relations [18,19].

Given the great diversity of games, sports, and physical activities that exist, one of the key problems is to identify objective indicators that facilitate a scientific classification that allows an understanding of any motor activity. According to the criterion of motor interaction, motor praxeology identifies two large families of TSGs: psychomotor TSGs in which participants do not have motor interaction with each other (e.g., long jump in athletics, swimming lane race) and socio-motor TSGs in which participants interact motorically with peers (e.g., cooperative games such as dances), with opponents (e.g., wrestling, tag games) or with peers and opponents (e.g., dodgeball, team sports).

The different categories of games can be regrouped according to whether or not they have a final score. That is, whether they have an end set of rules that identifies who wins and who loses, or whether they do not have a competition associated with an end result [20].

By participating in a game, players adapt to the internal logic of this practice and engage in motor behaviors, i.e., motor interventions charged with subjective meaning [18]. Motor behaviors bear witness to the performance of the participants with the unitary activation of the different dimensions of their personality. Passing the ball, escaping from an opponent or saving a teammate are examples of interventions that mobilize at the same time an energetic (biological), decisional (cognitive), relational (social) and emotional (affective) involvement [16].

From a gender perspective, scientific evidence has shown that, depending on the type of motor relationships, TSGs trigger different effects in the male and female genders in relation to emotional experience, decision-making, conflict and the intensity of motor relationships [21-23]. 
Despite the fact that these dimensions are intertwined, there are hardly any studies that interpret motor behaviors holistically, i.e., in a Multidimensional $360^{\circ}$ view [17].

In this research we used a traditional sports game (Elbow Tag) because its internal logic stimulates very particular interpersonal relationships (see methodological section).

The internal logic of the game of Elbow Tag triggers different types of problems for the players associated with decision-making, relations with other players, and energy expenditure [24].

To study decision-making, the theoretical foundations of motor praxeology have two universals: the network of role changes and the network of socio-motor sub-role changes [25].

In any game of Elbow Tag, the players intervene by constantly switching between the three roles. The cat becomes a mouse if it is captured; the mouse becomes a pitcher if it grabs one of the pairs with that role; the pitcher becomes a mouse if a mouse is placed on the other side of its pair. The transition through the roles can be represented by the network of role changes [24], as shown in Figure 1.

\section{Role Changes Network}

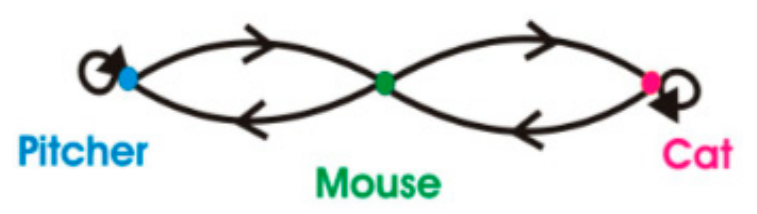

Figure 1. The network of role changes in the game of Elbow Tag.

Just as in everyday life, where we constantly adopt different roles (teacher, doctor, parent, researcher, etc.), in this game each role integrates different types of decisions. In order to study and reveal the decision-making offered by the internal logic of a game, motor praxiology incorporates the notion of the sub-role by referring to the more concrete decision units associated within each role [25]. In this game, each role attempts to solve different problems or decision units by integrating different sub-roles (see Figure 2).

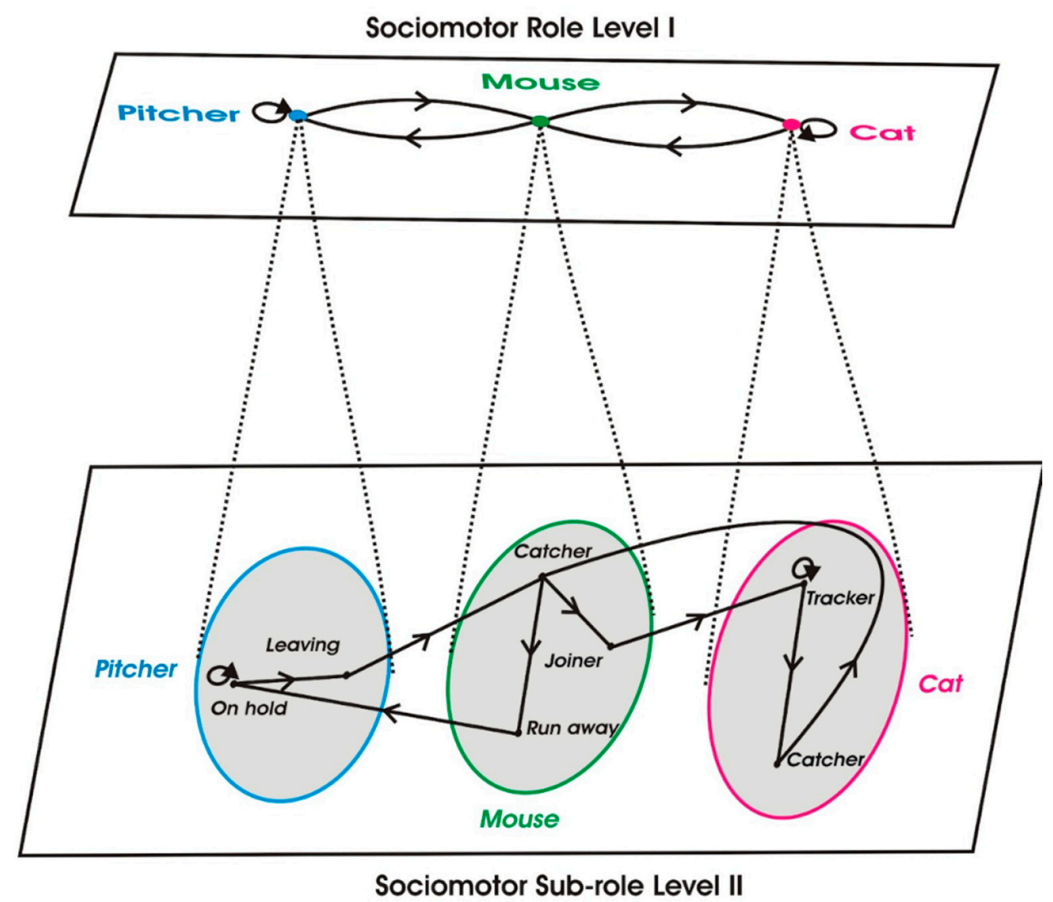

Figure 2. Role and sub-roles levels in the game of Elbow Tag. 
The decisions of players are also associated with an exchange of social interactions. TSGs are a miniature society where participants share interpersonal relationships [18].

The interpersonal relationships contained in the internal logic of the game of Elbow Tag can be explained by two universals: The Network of Motor Interactions and the Network of Scoring Interactions.

The Network of Motor Interactions represents the virtual canvas on which all ludic exchanges develop. It is undoubtedly the element where everything is to be played out according to the constraints of the internal logic, such as the ways of acting and communicating. Each sporting game stages its own universal, leading to extremely varied particular behaviors, very rich in relational consequences ( . . . . . By "Network of Motor Interactions" we mean the graph of which the vertices are players and the arcs represent the operational interactions authorized by the rules: passing, tackling, shooting, stealing, etc. [25] (p. 3).

This universal reveals that in the game of Elbow Tag, the players establish a binary relationship of counter-communication or negative communication, as the motor interaction between the participants is oppositional (the mouse opposes the cat) [24]. A first cursory glance at the game might suggest that the relationship between the mouse and pitcher is neutral. However, the interactive process at the heart of the game is relatively complex. It is an apparently binary relation-the mouse clings to a comrade-but, in reality, the relationship is ternary: by their attachment, the mouse has freed the second player of the pair, who becomes the new mouse in accordance with the universal of sociomotor roles. Sometimes the running mouse even directs their course so that the mouse-to-be standing player can be easily struck by the cat when the role change occurs, which creates a quaternary relationship [25] (p. 5).

The network of Scoring Interactions is a sub-network of the motor communication network. It indicates the ways in which the objectives of the game can be achieved, i.e., the ways in which success can be achieved [18].

The "universal of Scoring Interaction Network" applied to the game Elbow Tag enables the completion of the basic network of motor interactions. This universal shows the interpersonal interactions that favor the success of the participants in the game, i.e., they are the ones that provoke a role reversal in the participants: when the cat catches a mouse and when a mouse joins a pitcher without being caught [19] (p. 140).

However, successful or scoring actions in this game are not recorded as in sports, as it is not determined who has won or lost. At the end of the game there is no quantitative summary of the actions that caused a role reversal $[18,24]$. This is an original distinctive feature of these types of games.

When participating in each of the roles in the game of Elbow Tag, the players make decisions, communicate motorically and also perform actions with different energy expenditures. The physical effort involved in cat and mouse or Elbow Tag is unequal. The game of Elbow Tag is a duel between two participants (one against one); however, there is no high energy expenditure, although it may occur at certain moments during the intervention [24]. Participants in the pitcher role are waiting, while in the cat and mouse roles the energy expenditure will depend on the intensity proposed, mainly by the cat, maintaining different intensities intermittently (considering that the roles are also intermittent), interspersed with moments of recovery and pause [26].

Both girls and boys, when participating in the game of Elbow Tag, interpret the internal logic of the game in a unitary way and adapt in the best possible way when making decisions, interacting and managing their physical effort. However, there are hardly any studies that have investigated these $360^{\circ}$ Multidimensional chains of interwoven participation [17].

In the light of all these considerations, this study had the following objectives:

1. To determine the relationship between interpersonal relationships according to gender and two cognitive variables (role and sub-role), one relational variable (number of interactions), and two organic variables (steps and physical effort) in the game Elbow Tag. 
2. From a multidimensional point of view $\left(360^{\circ}\right.$ vision), to establish the predictive capacity of the cognitive variables (roles and sub-roles), relational (number of interactions between players), organic (physical effort and number of steps) and the gender of the players to establish the interpersonal relationships of boys and girls in the game Elbow Tag.

3. From a multidimensional point of view ( $360^{\circ}$ vision), to detect the strategic chains of boys and girls through temporal patterns (T-Patterns) in the game Elbow Tag.

\section{Materials and Methods}

\subsection{Study Design}

The study followed an associative strategy (exploring the functional relationship between variables) and corresponded to a comparative predictive design based on group comparison [27].

The application of an observational methodology should itself be considered a mixed methods approach [28]. The present study applied a type III design, inspired by the observational methodology N/P/M [29]. Therefore, the Nomothetic $(\mathrm{N})$ character was justified by the interest in investigating collective units of TSGs. It was considered Punctual (P) due to the fact that only one single recording was made, apart from a specific followup. On the other hand, linking Parlebas' conceptualization of roles and sub-roles [25] with their respective links to criteria and categories allowed us to identify the study as Multidimensional (M).

\subsection{Participants}

This study was performed with 147 university students $(\mathrm{M}=19.6, \mathrm{SD}=2.3)$ : 47 girls $(31.97 \%)$ and 100 boys $(68.02 \%)$ from the first course of physical activity and sport sciences at the University of Lleida, enrolled in the subject Theory and Practice of Motor Games. The students were divided in a random way into groups of 12 to 14 people to perform the game. The distribution between women and men maintained the same proportion as in the class group, with a predominance of the masculine gender over the feminine one.

All participants signed an express authorization authorizing their filming (Declaration of Helsinki). In addition, the study was reviewed and approved by the Ethics Committee for Clinical Research of the Catalan Sports Council [07/2019/CEICEGG].

\subsection{Procedure and Materials}

Figure 3 illustrates the four phases followed in the methodological strategies of this research.

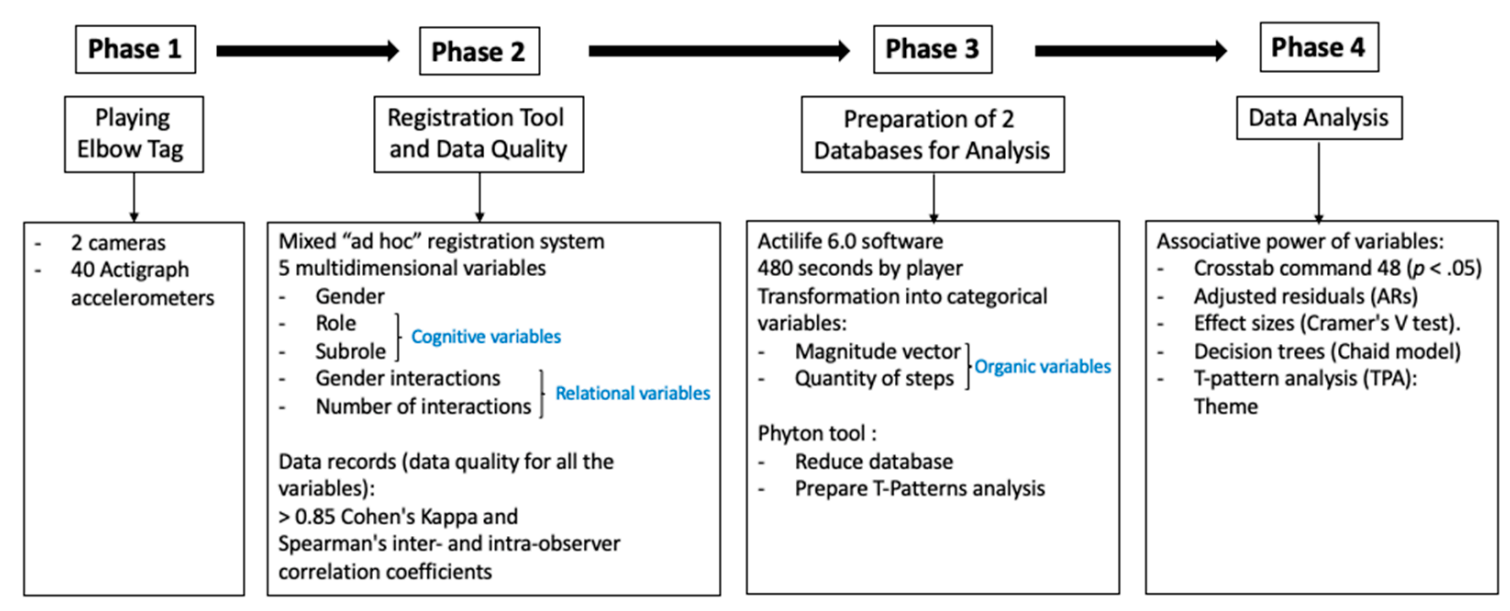

Figure 3. Phases followed in the methodological strategies. 


\subsubsection{Phase 1: Playing Elbow Tag}

Elbow Tag is a socio-motor game of opposition involving a local duel between two players. Although this TSG can be practiced in different ways, in this case, all but two participants organize themselves in couples, holding each other by the elbow and standing in a large circle, and the other two are designated "cat» (hunter) and «mouse» (hare). Pursued by the hunter, a hare finds its salvation by hooking to the free arm of one of the two players of any of the couples in the circle. In that very moment, the other player who was a member of the couple until that moment becomes the new hare, who must run away from the hunter at full speed and try to cling on to another couple in the circle. If the hare is touched before them, there is a swap of roles between the hare and the hunter. The most popular role among players is the hare because it allows a lot of fantasy, tricks, and feints. Some hares hang on after only a few seconds, while others extend their facetious provocations for several minutes [24].

According to [24], the Elbow Tag game offers the following role changes and sub-roles (Figure 4).

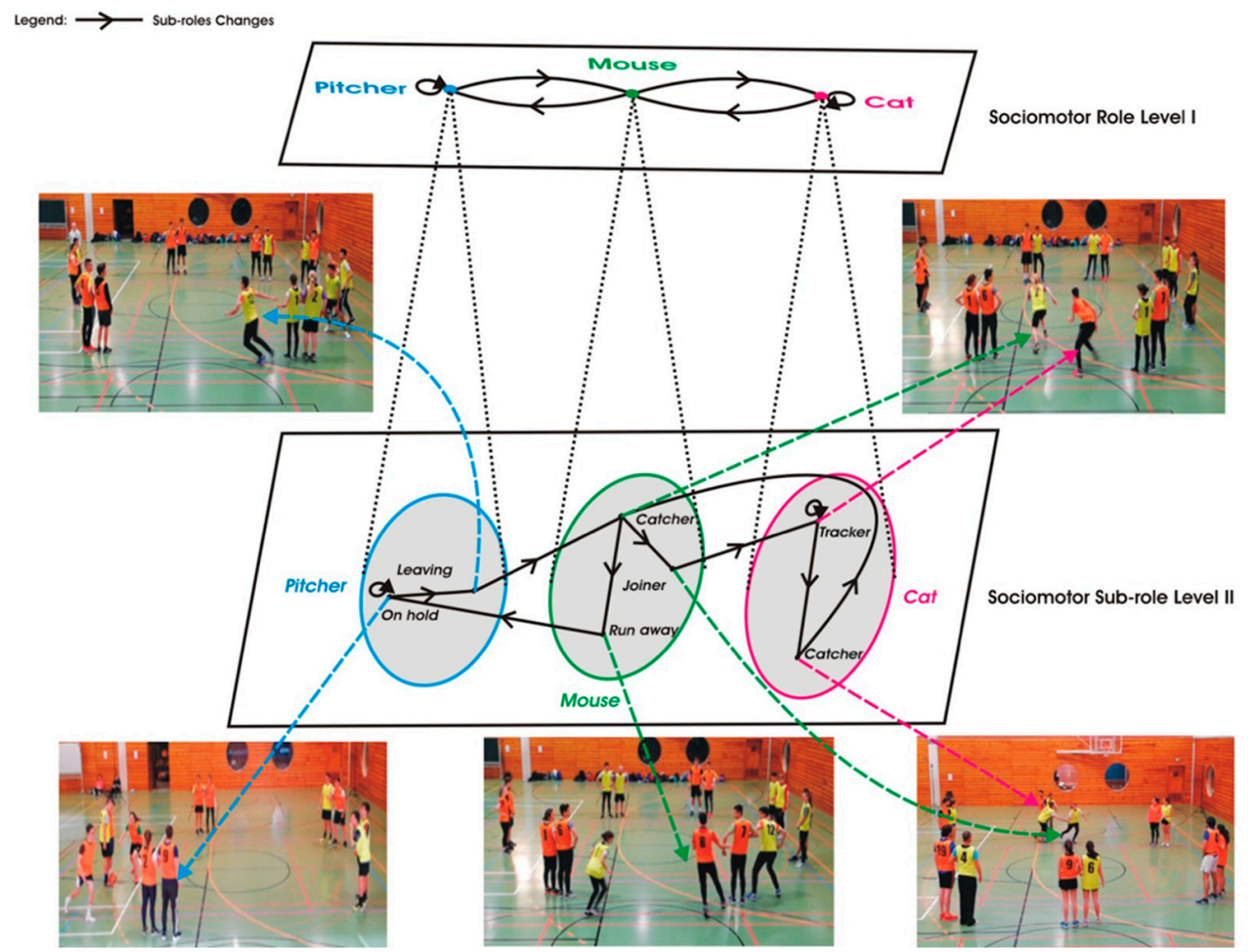

Figure 4. The network of role changes and the network of socio-motor sub-role changes in the game of Elbow Tag.

Pitcher's Role (P): Pitcher on Hold (POH): Player who is holding on to another pitcher, waiting for a mouse to hold on to them or to give them a way out; Pitcher Leaving (PL): Player who has let go of their partner (pitcher), because another player (MC) has grabbed them. This player becomes a runaway mouse (MX).

Cat's role (C): Cat Tracker (CT): player who tries to capture another player in the role of a mouse; Cat Catcher (CC): Player who is in that instant of capturing the mouse.

Mouse's role (M): Mouse Run Away (MX): Player running away from the cat; Mouse Catcher (MC): Runaway mouse (MX): which at the same moment is captured by the cat; Mouse Joiner (MJ): the mouse on the run (MX) that hooks themselves to a pitcher player to avoid being caught by the cat.

Due to the complexity of the system of motor communication, Elbow Tag is an excellent game to observe the interpersonal relationships between the female and male 
genders. From this point of view, it is interesting to identify the gender of the motor interactions that can originate in the constant exchange of roles: (a) Male interpersonal relationship (BB): Motor interaction between cat-mouse or mouse-pitcher roles takes place between two boys; (b) Female interpersonal relationship (GG): Motor interaction between cat-mouse or mouse-pitcher roles takes place between two girls; (c) Girl-Boy interpersonal relationship (GB): Motor interaction between cat-mouse or mouse-pitcher roles is activated by a girl towards a boy; (d) Boy-Girl interpersonal relationship (BG): Motor interaction between cat-mouse or mouse-pitcher roles is activated by a boy towards a girl.

The Elbow Tag game was carried out by the regular teacher of the course during their regular class schedule. It was put into practice for several minutes in order for it to be understood by the players, and tests were made for its filming before its playing for research purposes. Afterwards, the students asked questions, which the teacher answered. Two days later, the Elbow Tag game began starting, with the performance first of a series of warm up exercises by the participants in order for them to be adapted to the new physical effort.

To identify the exact start and end on the accelerometers, the players were asked to perform several vertical jumps (for $10 \mathrm{~s}$ ) and then to remain still (for $5 \mathrm{~s}$ ). The time for each game was previously stipulated for all groups at $8 \mathrm{~min}$.

In order to perform the recording procedure, two cameras (Sony DCR-SX21 model) were used. The recording time was continuous, without interruptions. Fourteen ActiGraph GT3X+ accelerometers (ActiGraph LLC, Pensacola, FL, USA) were used to quantify: (i) the amount of energy expended by each player, and (ii) the time spent at each of the different levels of intensity or energy while the game was developed.

\subsubsection{Phase 2: Registration Tool and Data Quality}

Within the research group (GIAM), a mixed 'ad hoc' registration system was designed with exhaustive and mutually exclusive categories. This premise is essential to understand that each registry would correspond to a single role or criterion and a single sub-role or category [30].

Five variables corresponding to the Multidimensional participation of the players were recorded: gender, two cognitive variables (role and sub-role), and two relational variables (gender interactions and number of interactions).

The categories of roles and sub-roles were initially identified deductively, according to the theoretical reference framework [18,31], and then in an exploratory or inductive manner as a result of the observations carried out by the team of observers (e.g., incorporation of the role and sub-role in conflict). Once all the categories of the different variables to be observed had been identified, a manual for the observers was drawn up, describing the categories and degrees of freedom.

Systematic observation of the game using observational methodology confirmed the presence of three roles (pitcher, cat, and mouse). At the same time, the existence of conflicts or disagreements in the interpersonal relationships of the participants was also observed. For this reason, a fourth role was added specifically for these circumstances called Conflict $(\mathrm{CF})$, with the sub-role in conflict $(\mathrm{CF})$, when two players stopped intervening in the game to discuss, resolve or settle a disagreement about some game action.

To guarantee the quality of the observational data, four researchers were selected under the criteria of being members of the GIAM group and having at least two years of experience in the use of systematic observation methodology.

With the help of Spss v. 25 software (SPSS Inc., Chicago, IL, USA) and in order to verify the quality of the records obtained, Cohen's Kappa and Spearman's inter- and intraobserver correlation coefficients were applied. Consequently, about $10 \%$ of the total records were selected. In pairs, while observers 1 and 2 made the first records, observers 3 and 4 agreed on their own records in separate locations. Two weeks after the end of this first phase, and respecting the same pairs of observers, the experience was repeated to record the videos again. Thus, both the intra-observer coefficients (Evaluator 1 and 2) with (Evaluator 
1 and 2) or (Evaluator 3 and 4) with (Evaluator 3 and 4) and inter-observer coefficients (Evaluator 1 and 2) with (Evaluator 3 and 4 ) exceeded the reliability coefficients of 0.85 accepted in social science (values of 0.85 ). This result ensured the quality of the records.

\subsubsection{Phase 3: Preparation of Two Databases for Analysis}

Events were associated by seconds between the set of variables for each player. The observational procedure carried out by two observers allowed the recording of data of the variables role/sub-role, steps/physical effort, gender/gender interactions/number of interactions from videos, and events developed by the players.

The data recorded by the accelerometers were downloaded through the ActiLife 6.0 software (ActiGraph, Pensacola, FL, USA). The data were integrated in periods of $1 \mathrm{~s}$, obtaining $480 \mathrm{~s}$ per participant. The intensity of the effort expressed by means of the magnitude vector in counts per second was transformed into a categorical variable using the cut-off points (sedentary: 0-2 CPS, light: >2-34 CPS, moderate: >34 a 100 CPS, or vigorous: $>34$ a 100 CPS). The quantity of steps was also considered as an energy variable and was transformed into a categorical variable (Low: 0-1 steps, light: 2 steps, moderate: 3 steps, or high: $>4$ steps).

Once all the variables were categorized, different statistical analyzes were performed (cross-tab, decision trees and T-patterns). Previously, for the T-pattern analysis, it was necessary to perform a cleaning process of repeated records [17]. For this, a script designed with the help of the Phyton tool was used. The premise was to eliminate event repetitions that appeared for more than one second in a row (Table 1). In this way, two objectives were achieved: on the one hand, to reduce the database and, on the other hand, to prepare it to be analyzed by T-pattern analysis (TPA) $[32,33]$.

Table 1. Simulation of the process used to remove repeated events from original database (second by second) to T data in order to be analyzed by THEME v.6.

\begin{tabular}{|c|c|c|c|c|}
\hline Seconds & $\begin{array}{l}\text { Categories } \\
\text { (8 Events) }\end{array}$ & Seconds & $\begin{array}{l}\text { Categories } \\
\text { (4 Events) }\end{array}$ & $\begin{array}{l}\text { Duration } \\
\text { (Interval) }\end{array}$ \\
\hline 60 & GB CT HR V SS & 60 & GB CT HR V SS & 3 \\
\hline 61 & GB CT HR V SS & 63 & GB CT HR V LS & 2 \\
\hline 62 & GB CT HR V SS & & GG POH LR L LS & 1 \\
\hline 63 & GB CT HR V LS & 66 & GG POH LR S LS & 2 \\
\hline 64 & GB CT HR V LS & & & \\
\hline 65 & GG POH LR L LS & & & \\
\hline 66 & GG POH LR S LS & & & \\
\hline 67 & GG POH LR S LS & & & \\
\hline
\end{tabular}

Note: In this example it is noted that the data corresponding to the 8 events, one per second (One Row $=$ One Second) (from 60 to $67 \mathrm{~s}$ ) were transformed into four intervals (One Row = Time Interval: $3^{\prime \prime} ; 2^{\prime \prime} ; 1^{\prime \prime} ; 2^{\prime \prime}$ ) (from 60 to $66 \mathrm{~s}$ ) to be analyzed as T-Data.

\subsubsection{Phase 4: Data Analysis}

The associative power of the variables was addressed by Crosstab command $(p<0.05)[34]$ with adjusted residuals (ARs) $>1.96$ or $<-1.96$, as well as their respective effect sizes (Cramer's V test). The following values were used to interpret the effect sizes: $0.10=$ small effect, $0.30=$ medium effect, and $0.50=$ large effect [35].

On the other hand, a supervised learning model was applied, belonging to the decision trees: the chaid model. The parameters for the construction of the tree were: (i) Pearson's chi-squared test, (ii) number of cases by nodes (parent $n \geq 100$, children $n \geq 50$ ), (iii) crossvalidation. All analyses were performed with the SPSS v.25 tool (SPSS Inc., Chicago, IL, USA).

Finally, T-pattern analysis (TPA) was performed using the THEME v.6 PatternVision Ltd. (Reykjavik, Iceland, available online: www.patternvision.com, accessed on 15 June 
2021) tool [36-39]. TPA applies an algorithm that reveals the emergence of behavioral sets, overcoming the effect of chance, over given time intervals. A T-pattern is a combination of events that occur separated by a time distance that remains invariant relative to the null hypothesis that each event or behavior is independent and randomly distributed over the time.

Following [38] (pp. 94-95), 'if A is an earlier and B a later component of the same recurring T-pattern, then, after an occurrence of $A$ at $t$, there is an interval $[t+d 1, t+d 2]$ ( $\mathrm{d} 2 \geq \mathrm{d} 1 \geq \mathrm{d} 0$ ) that tends to contain at least one occurrence of $B$ more often than would be expected by chance'. We looked for the most complex T-patterns $(p<0.005)$ and a minimum of 20 events in the most determinant roles of the game, such as cat (MX) and mouse (CT), in the two interaction options with the opposite gender (BG and GB).

\section{Results}

The following results respond to the three objectives of this study.

For the first objective, cross-tabulations examined significance $(p<0.05)$ and effect size by relating variables in pairs.

Subsequently, for the second objective, classification trees showed the hierarchical strength of the variables used in this study: two cognitive variables (role and sub-role), one relational variable (number of interactions), two organic variables (steps and physical effort) and gender, to predict the type of interpersonal relationships (male: BB; female: GG; or mixed: $\mathrm{BG}, \mathrm{GB}$ ) originated in the game of Elbow Tag.

Finally, for the third objective, the use of TPA allowed us to detect T-Patterns $(p<0.005)$ of Multidimensional strategic chains considering all variables ( $360^{\circ}$ vision).

The results presented below show the relationship between the variables which range from binary relationships to the vision of multidimensional strategic chains (360).

\subsection{Type of Interpersonal Relationships between Girls and Boys}

Firstly, it should be noted that $64,876 \mathrm{~s}$, corresponding to different motor interactions in the game of Elbow Tag, were examined during eight minutes: $42,263 \mathrm{~s}(65.14 \%)$ originated by the boys and $22,613 \mathrm{~s}(34.86 \%)$ by the girls.

Statistically significant differences were observed $\left(x^{2}[3]=56,788.15, p \leq 0.001, E S=0.936\right)$ by comparing the type of interpersonal relationships between the two genders (Table 2). The boys were predominantly involved in male interpersonal relationships, while the majority of the girls' interpersonal relationships were mixed when receiving a boy-initiated interaction. The second most common type of interpersonal relationships for the boys was mixed (GB), while for the girls it was with the same gender (GG). The boys hardly originated mixed interpersonal relationships starting from the male gender over the female gender (BG). Similarly, mixed interpersonal relationships from girls to boys were in the minority among females (GB).

Number of Interactions in the Interpersonal Relationships

It was found that slightly more than half of the records were interventions, with there being a light number of interpersonal relationships (LR: 2 relationships), followed by actions with very few interpersonal relationships (SR: 1 relationship); then there were actions with a moderate level of relationships (MR: 3-4 relationships). Actions with a high number of relationships were in the minority $(\mathrm{HR}:=>5)($ Table 3$)$. 
Table 2. Interpersonal Relationships between girls and boys analyzed by seconds.

\begin{tabular}{|c|c|c|c|}
\hline \multicolumn{2}{|c|}{ Interactions by Gender } & \multicolumn{2}{|c|}{$\begin{array}{c}\text { Gender } \\
\left.x^{2}[3]=56,788.15, p \leq 0.001, E S=0.936\right)\end{array}$} \\
\hline & & B & G \\
\hline \multirow{4}{*}{ Boy-Boy (BB) } & $M$ & 28,067 & 0 \\
\hline & $\%$ & 66.4 & 0 \\
\hline & $A R$ & 16.7 & -162.7 \\
\hline & $M$ & 670 & 13,725 \\
\hline \multirow{3}{*}{ Boy-Girl (BG) } & $\%$ & 1.6 & 60.7 \\
\hline & $A R$ & -172.7 & 172.7 \\
\hline & $M$ & 13,526 & 1314 \\
\hline \multirow[t]{3}{*}{ Girl-Boy (GB) } & $\%$ & 32 & 5.8 \\
\hline & $A R$ & 75.7 & -75.7 \\
\hline & $M$ & 0 & 7574 \\
\hline \multirow{2}{*}{ Girl-Girl (GG) } & $\%$ & 0 & 33.5 \\
\hline & $A R$ & -126.6 & 126.6 \\
\hline Total & & 42,263 & 22,613 \\
\hline
\end{tabular}

Table 3. Interpersonal Relationships in the Relational Dimension (Number of interactions) analyzed by seconds.

\begin{tabular}{|c|c|c|c|c|c|c|}
\hline \multirow{2}{*}{\multicolumn{2}{|c|}{ Interactions by Gender }} & \multicolumn{4}{|c|}{$\begin{array}{c}\text { Relational Dimension } \\
\left(x^{2}[9]=469.965, p \leq 0.001, E S=0.049\right)\end{array}$} & \multirow[t]{2}{*}{ Total } \\
\hline & & HR & LR & MR & SR & \\
\hline \multirow{3}{*}{$\begin{array}{l}\text { Boy-Boy } \\
\text { (BB) }\end{array}$} & $M$ & 1876 & 15,786 & 4501 & 5904 & \multirow[t]{3}{*}{28,067} \\
\hline & $\%$ & 43.3 & 44.1 & 43.5 & 41 & \\
\hline & $A R$ & 0.1 & 4.7 & 0.5 & -6.2 & \\
\hline \multirow{3}{*}{$\begin{array}{l}\text { Boy-Girl } \\
\text { (BG) }\end{array}$} & $M$ & 776 & 7679 & 2351 & 3589 & \multirow[t]{3}{*}{14,395} \\
\hline & $\%$ & 17.9 & 21.4 & 22.7 & 24.9 & \\
\hline & $A R$ & -7.0 & -5.0 & 1.4 & 0 & \\
\hline \multirow{3}{*}{$\begin{array}{l}\text { Girl-Boy } \\
\text { (GB) }\end{array}$} & $M$ & 876 & 8328 & 2082 & 3554 & \multirow[t]{3}{*}{14,840} \\
\hline & $\%$ & 20.2 & 23.3 & 20.1 & 9.4 & \\
\hline & $A R$ & -4.3 & 2.6 & -7.3 & 5.9 & \\
\hline \multirow{3}{*}{$\begin{array}{l}\text { Girl-Girl } \\
\text { (GG) }\end{array}$} & $M$ & 801 & 4007 & 1418 & 1348 & \multirow[t]{4}{*}{7574} \\
\hline & $\%$ & 18.5 & 11.2 & & 9.4 & \\
\hline & $A R$ & 14.5 & -4.2 & 7.0 & -9.8 & \\
\hline Total & & 4329 & 35,800 & 10,352 & 14,395 & \\
\hline
\end{tabular}

Male interpersonal relationships (BB) were mostly with one (SR) or two different people (LR), followed by interpersonal relationships with three (MR) or four people (HR).

Female interpersonal relationships (GG) were mainly with two (LR) different participants, although they also presented similar values when interacting with one (SR), three (MR), or four different people (HR) (Table 3).

Mixed interpersonal relationships caused by men (BG) were mostly relationships with one (SR) or two (LR) different protagonists. The percentage of relationships with three (MR) or four people (HR) were considerably lower (Table 3).

In the mixed interpersonal relationships generated by women (GB), there were mostly relationships with one (SR) or two (LR) different protagonists. The percentage of relationships with three (MR) or four people (HR) was considerably lower (Table 3).

Significant differences $\left(x^{2}[9]=469.965, p \leq 0.001, E S=0.049\right)$ were observed when comparing girls' and boys' same- and mixed-gender interpersonal relationships with the number of interactions between participants (Table 3).

It is observed that, when interacting with three persons (MR), mixed interpersonal relationships elicited by girls (GB) were significantly higher than interpersonal relationships elicited with the same gender GG (Table 3). When interacting with two people (LR), the 
mixed interpersonal relationships elicited by girls (GB) were significantly higher than the interactions elicited with the same gender (GG) and the opposite gender (BG) (Table 3).

\subsection{Type of Decisions (Sub-Roles) in the Interpersonal Relationships}

A total of 64,876 s were recorded corresponding to decisions or sub-roles of the Elbow Tag game (CC, CT, PL, POH, MX, MJ, MC). The majority of sub-roles corresponded to the Pitcher role $(\mathrm{POH})$. In the second group, the cat role $(\mathrm{CT})$ accounted for the second highest number of decisions. Mouse decisions (MC, MJ, MX) were less numerous than for the other roles. Observation of the interventions identified that the conflict role and sub-role were very rarely present in the game $(\mathrm{CF}=402,0.62 \%)$.

Male interpersonal relationships (BB) in the Pitcher role (POH) were in the majority compared to the cat role (CT), the mouse role (MX), and the conflict role (CF) (Table 4).

Table 4. Interpersonal Relationships in the Cognitive Dimension analyzed by seconds.

\begin{tabular}{|c|c|c|c|c|c|}
\hline \multirow[t]{2}{*}{$\begin{array}{c}\text { Interactions } \\
\text { by Gender }\end{array}$} & \multicolumn{3}{|c|}{$\begin{array}{c}\text { Cognitive Dimension } \\
\left(x^{2}[21]=667.276, p \leq 0.001 ;\right. \\
E S=0.059)\end{array}$} & \multirow[b]{2}{*}{ POH } & \multirow[t]{2}{*}{ Total } \\
\hline & & CT & MX & & \\
\hline \multirow{3}{*}{ Boy-Boy (BB) } & $M$ & 1555 & 1405 & 23,815 & \multirow[t]{3}{*}{26,775} \\
\hline & $\%$ & 43.2 & 45.4 & 43.1 & \\
\hline & $A R$ & -0.1 & 2.4 & -2.3 & \\
\hline \multirow{3}{*}{ Boy-Girl(BG) } & $M$ & 554 & 407 & 12,802 & \multirow[t]{3}{*}{13,763} \\
\hline & $\%$ & 25.4 & 13.2 & 23.2 & \\
\hline & $A R$ & -10.1 & -12.4 & 14.2 & \\
\hline \multirow{3}{*}{$\begin{array}{l}\text { Girl-Boy } \\
\text { (GB) }\end{array}$} & $M$ & 1187 & 1038 & 11,964 & \multirow[t]{3}{*}{14,189} \\
\hline & $\%$ & 33 & 33.5 & 21.6 & \\
\hline & $A R$ & 14.9 & 14.4 & -18.0 & \\
\hline \multirow{3}{*}{$\begin{array}{l}\text { Girl-Girl } \\
\text { (GG) }\end{array}$} & $M$ & 303 & 247 & 6703 & \multirow[t]{3}{*}{7253} \\
\hline & $\%$ & 8.4 & 8 & 12.1 & \\
\hline & $A R$ & -6.3 & -6.6 & 8.6 & \\
\hline Total & & 3599 & 3097 & 55,284 & 61,980 \\
\hline
\end{tabular}

Female interpersonal relationships (GG) in the Pitcher role (POH) were in the majority compared to the cat role (CT), the mouse role (MX), and the conflict role (CF) (Table 4).

Mixed interpersonal relationships (BG) in the Pitcher role $(\mathrm{POH})$ were in the majority compared to the cat role (CC Cat-Catcher $=0.55 \%$, CT Cat-Tracker $=8.00 \%$ ), the mouse role (MC Mouse-Catcher $=1.25 \%$, MJ Mouse-Joiner $=0.55 \%$, MX Mouse-Run $=6.99 \%$ ), and the Conflict role (CF Conflict $=0.67 \%$ ).

Mixed interpersonal relationships (GB) in the Pitcher role (POH) were in the majority compared to the cat role (CT), the mouse role (MX), and the conflict role (CF) (Table 4).

Statistically significant differences $\left(x^{2}[21]=667.276, p \leq 0.001 ; E S=0.059\right)$ were observed when comparing the interpersonal relationships that took place in the sub-roles associated with the three roles of the Elbow Tag game (Table 4).

Of the total sub-roles, significant differences (Table 4) were found in four of them (CT, MX, POH, CF) with regard to the interpersonal relationships. It is observed that, in the sub-roles of Cat-Catcher (CT), Mouse-Run (MX), and Pitcher-On hold (POH), the mixed interpersonal relationships elicited by boys (BG) were significantly lower than the interpersonal relationships elicited by girls (GB) (Table 4).

\subsection{The Physical Effort in the Interpersonal Relationships}

Two variables are considered in this section: physical effort (MV) and number of steps.

\subsubsection{Physical Effort in the Interpersonal Relationships (MV)}

It was found that most of the records were sedentary interventions (S), followed by light actions (L), then vigorous actions (V), and finally moderate actions (M) (Table 5). 
Table 5. Interpersonal Relationships in the Organic Dimension (VM) analyzed by seconds.

\begin{tabular}{|c|c|c|c|c|c|c|}
\hline \multirow{2}{*}{\multicolumn{2}{|c|}{ Interactions by Gender }} & \multicolumn{4}{|c|}{$\begin{array}{c}\text { Organic (VM) } \\
\left(x^{2}[9]=463.424, p \leq 0.001 ; E S=0.049\right)\end{array}$} & \multirow[t]{2}{*}{ Total } \\
\hline & & $\mathbf{L}$ & $\mathbf{M}$ & $S$ & V & \\
\hline \multirow{3}{*}{$\begin{array}{l}\text { Boy-Boy } \\
\text { (BB) }\end{array}$} & $M$ & 4918 & 2349 & 16,928 & 3872 & \multirow[t]{3}{*}{28,067} \\
\hline & $\%$ & 43.4 & 44.5 & 42.8 & 44.3 & \\
\hline & $A R$ & 0.2 & 1.9 & -2.7 & 2.1 & \\
\hline \multirow{3}{*}{$\begin{array}{l}\text { Boy-Girl } \\
\quad \text { (BG) }\end{array}$} & $M$ & 2347 & 1054 & 9526 & 1468 & \multirow[t]{3}{*}{14,395} \\
\hline & $\%$ & 20.7 & 20 & 21.1 & 16.8 & \\
\hline & $A R$ & -4.2 & -4.1 & 14.7 & -13.0 & \\
\hline \multirow{3}{*}{$\begin{array}{l}\text { Girl-Boy } \\
\text { (GB) }\end{array}$} & $M$ & 2600 & 1253 & 8423 & 2564 & \multirow[t]{3}{*}{14,840} \\
\hline & $\%$ & 22.9 & 23.7 & 21.3 & 29.3 & \\
\hline & $A R$ & 0.1 & 1.5 & -11.8 & 15.5 & \\
\hline \multirow{3}{*}{$\begin{array}{l}\text { Girl-Girl } \\
\text { (GG) }\end{array}$} & $M$ & 1477 & 626 & 4635 & 836 & \multirow[t]{4}{*}{7574} \\
\hline & $\%$ & 13 & 11.9 & 11.7 & 9.6 & \\
\hline & $A R$ & 4.9 & 0.4 & 0.6 & -6.6 & \\
\hline Total & & 11,342 & 5282 & 39,512 & 8740 & \\
\hline
\end{tabular}

In male interpersonal relationships (BB), physical exertion (MV) was mainly sedentary (S), followed by light (L), vigorous (V), and moderate (M) exertion (Table 5).

In female interpersonal relationships (GG), physical exertion (MV) was mainly sedentary (S), followed by light (L) vigorous (V) and moderate (M), exertion (Table 5).

In the mixed interpersonal relationships generated by men (BG), physical exertion (MV) was mainly sedentary (S), followed by light (L) vigorous $(\mathrm{V})$, and moderate $(\mathrm{M})$ efforts (Table 5).

In the mixed interpersonal relationships generated by females (GB), physical exertion (MV) was mainly sedentary (S), followed by light (L) vigorous (V), and moderate (M) exertion (Table 5).

In relation to physical effort (MV), there were significant differences $\left(x^{2}[9]=463.424\right.$, $p \leq 0.001 ; E S=0.049)$ when relating this variable to the different interpersonal relationships of girls and boys (Table 5).

Of the four categories of physical effort (S, L, M, V), differences were found in three of them. It is observed that sedentary (S) and vigorous (V) efforts were mostly performed in interpersonal relationships between boys (BB). The highest value for light effort was among boys and girls (BG). Finally, the most significant vigorous exertions occurred more frequently from girls to boys (GB) than from boys to girls (BG) (Table 5).

\subsubsection{The Number of Steps in the Interpersonal Relationships}

It was found that most of the records were interventions with a light number of steps (LS: 2 steps), followed by actions with very few steps (SS: $0-1$ steps), and then by actions with a moderate level of steps (MS: 3 ). Actions with a high number of steps were in the minority (HS: $=>4$ ) $($ Table 6$)$. 
Table 6. Interpersonal Relationships in the Organic Dimension (Steps) analyzed by seconds.

\begin{tabular}{|c|c|c|c|c|c|}
\hline \multirow{2}{*}{\multicolumn{2}{|c|}{ Interactions by Gender }} & \multicolumn{3}{|c|}{$\begin{array}{c}\text { Organic (Steps) } \\
\left(x^{2}[9]=271.010, p \leq 0.001 ; E S=0.037\right)\end{array}$} & \multirow[t]{2}{*}{ Total } \\
\hline & & SS & LS & MS & \\
\hline \multirow{3}{*}{$\begin{array}{l}\text { Boy-Boy } \\
\quad \text { (BB) }\end{array}$} & $M$ & 1825 & 25,761 & 460 & \multirow[t]{3}{*}{28,046} \\
\hline & $\%$ & 44.8 & 43.1 & 43.6 & \\
\hline & $A R$ & 2.1 & -2.1 & 0.2 & \\
\hline \multirow{3}{*}{$\begin{array}{l}\text { Boy-Girl } \\
\text { (BG) }\end{array}$} & $M$ & 665 & 13,552 & 172 & \multirow[t]{3}{*}{13,389} \\
\hline & $\%$ & 16.3 & 22.7 & 16.3 & \\
\hline & $A R$ & -9.3 & 10.6 & -4.7 & \\
\hline \multirow{3}{*}{$\begin{array}{l}\text { Girl-Boy } \\
\text { (GB) }\end{array}$} & $M$ & 1228 & 13,272 & 331 & \multirow[t]{3}{*}{14,831} \\
\hline & $\%$ & 30.2 & 22.2 & 31.3 & \\
\hline & $A R$ & 11.4 & -13.3 & 6.6 & \\
\hline \multirow{3}{*}{$\begin{array}{l}\text { Girl-Girl } \\
\text { (GG) }\end{array}$} & $M$ & 354 & 7123 & 93 & \multirow[t]{4}{*}{7570} \\
\hline & $\%$ & 8.7 & 11.9 & 8.8 & \\
\hline & $A R$ & -6.1 & 6.9 & -2.9 & \\
\hline Total & & 4072 & 59,708 & 1056 & \\
\hline
\end{tabular}

In male interpersonal relationships (BB), interventions were mostly in 2 steps (LS), followed by interventions with 1 or 0 steps (SS), three steps (MS), and more than four steps (HS) (Table 6).

In female interpersonal relationships (GG), the interventions were mostly in 2 steps, followed by interventions with 1 or 0 steps (LS), three steps (MS), and more than four steps (HS) (Table 6).

In the mixed interpersonal relationships generated by men (BG), the interventions were mostly in 2 steps (LS), followed by interventions with 1 or 0 steps (SS), three steps (MS), and more than four steps (HS) (Table 6).

In the mixed interpersonal relationships generated by women (GB), the interventions were mostly in 2 steps ((LS), followed by interventions with 1 or 0 steps (SS), three steps (MS), and more than four steps (HS) (Table 6).

Of the four categories of the number of steps (SS, LS, MS, VS), significant differences were found in three of them when considering the interpersonal relationships $\left(x^{2}[9]=271.01, p \leq 0.001 ; E S=0.037\right)$ (Table 6).

It is observed that a lower number of steps (SS) were more present in male (BB) interpersonal relationships compared to between girls and boys (GB), boys and girls (BG), and girls and girls (GG) (Table 6).

Light steps (LS) were more present in male (BB) interpersonal relationships compared to boy-girl (BG), girl-boy (GB) and girl-girl (GG) interpersonal relationships (Table 6).

Moderate steps (MS) were more present in interpersonal relationships between girls and boys (GB), compared to interpersonal relationships between boys and girls (GB) and girls and girls (GG) (Table 6).

\subsection{Multidimensional Results 1. Predictive Capacity of the Variables (Decisional, Relational, Organic) on Male, Female, and Mixed Interpersonal Relationships}

The classification tree technique was used to analyze the predictive capacity of the sub-role variables (decisional), number of interactions (relational), steps and physical effort (organic), and the variable of gender on the multidimensional behavior of male, female and mixed interpersonal relationships.

The tree identified gender (Boys and Girls) as the first predictive variable for identifying interpersonal relationships between participants (nodes 1 and 2), with statistically significant differences found between boys and girls $\left(x^{2}[3]=56,788, p \leq 0.001\right)$.

Decisions (sub-roles) was the second predictive variable for both boys $\left(x^{2}[6]=11,604.748\right.$, $p \leq 0.001)$ and girls $\left(x^{2}[4]=17,613.100, p \leq 0.001\right)$. Boys' interpersonal relationships (Figure 5), were mainly with other boys in the sub-roles CT (node 3), CC, MC, POH, CF (Node 4), MX (Node 5) and PL, MJ (node 6). 


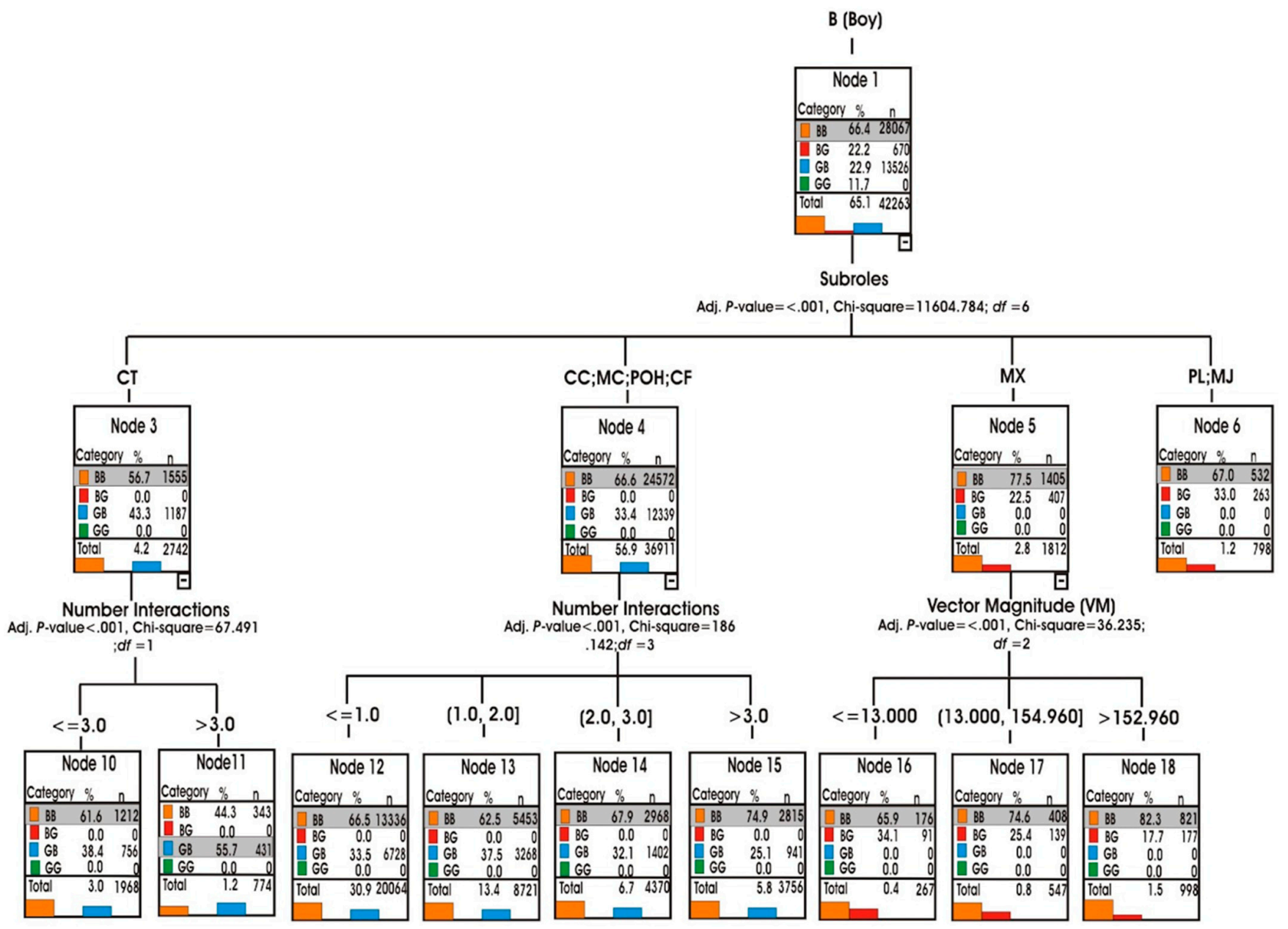

Figure 5. Predictive Model of Variables (decisional, relational, organic) on Interpersonal Relationships according to Male Gender.

The third predictive variable for determining interpersonal relationships between participants was the number of interactions between them (Figure 5).

In the CT sub-role $\left(x^{2}[1]=67.491, p \leq 0.001\right)$, the interpersonal relationships of boys with boys were mainly less than or equal to 3 (node 10), while when there were more than 3 interactions, these were mainly with girls (node 11).

In the sub-roles CC, MC, $\mathrm{POH}, \mathrm{CF}\left(x^{2}[3]=186.142, p \leq 0.001\right)$, the highest number of interactions (node $12,13,14,15$ ) were mainly with boys (BB).

In the sub-role MX, the third predictor variable was the intensity of exertion (MV) $\left(x^{2}\right.$ $[2]=36.235, p \leq 0.001)$. The interpersonal relationships between boys and boys (BB) at all levels of physical exertion intensity (sedentary, light, moderate, vigorous) (node 16, 17, 18) were larger than the other possible interpersonal relationships according to gender (BG, GB, GG).

In the case of girls (Figure 6), and considering the sub-roles as the second predictive variable, it was observed that interpersonal relationships were mainly between boys and girls (BG) in the sub-roles CT, CC, MC, POH, CF (node 7), and girls and boys (GB) in the sub-roles MX (node 8), PL and MJ (node 9). 


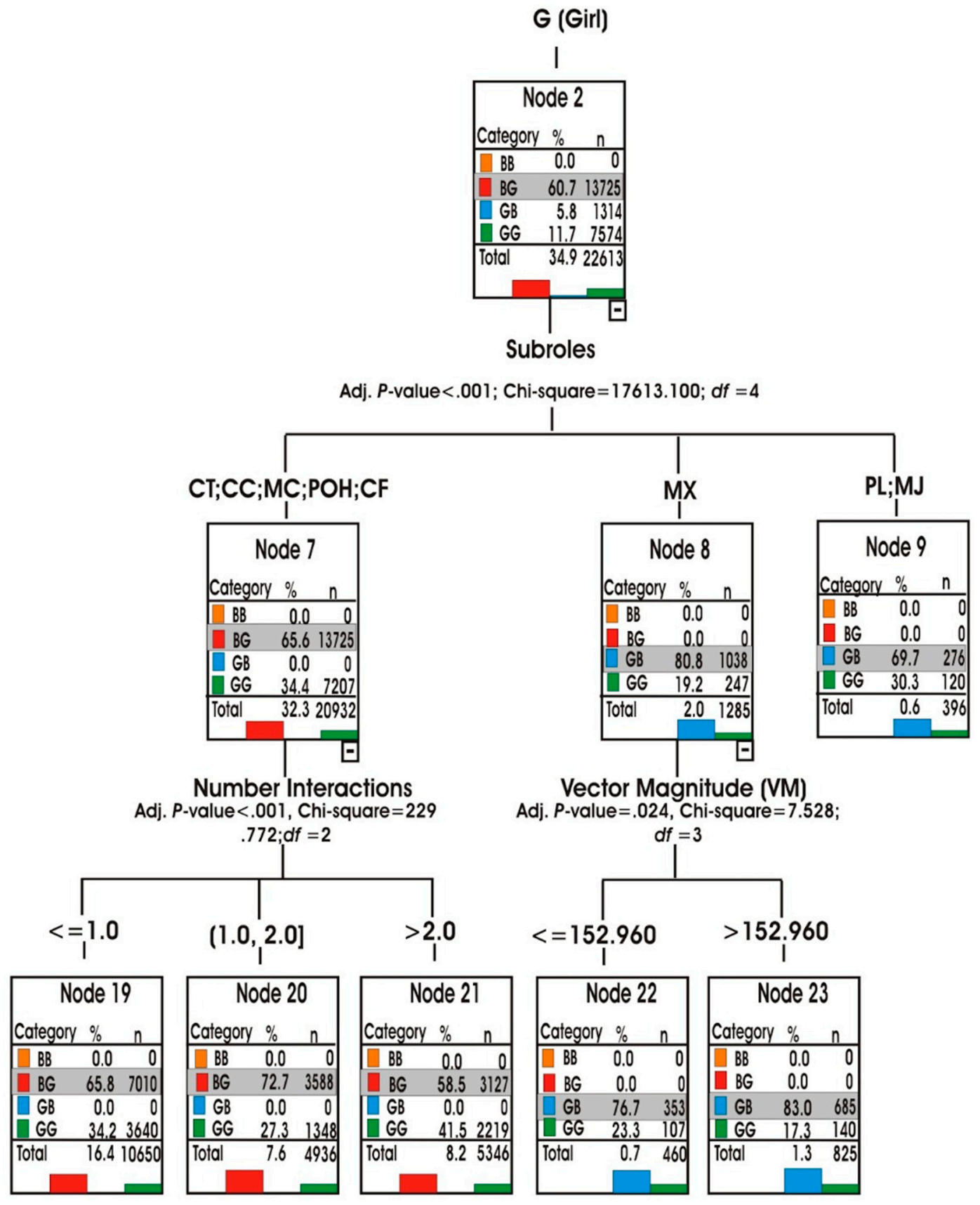

Figure 6. Predictive Model of the Variables (Decisional, Relational, Organic) on Interpersonal Relationships according to Female Gender.

The third predictive variable for determining interpersonal relationships between participants was the number of interactions between them in the sub-roles. In the sub-roles CT, CC, CF, MC, POH, significant differences $\left(x^{2}[2]=229.772, p \leq 0.001\right)$ were found in the number of interactions between players. In the Low (1), Slight (2), and Moderate (>2) cases, the interactions were mainly between boys and girls (node 19, node 20, node 21).

In the sub-role $\mathrm{MX}$, the third predictive variable was the intensity of exertion (MV) $\left(x^{2}[1]=7.528, p \leq 0.001\right)$. The interpersonal relationships between girls and boys (GB) at all levels of physical exertion intensity (sedentary, light, moderate, vigorous) were greater than the other possible interpersonal relationships (node 22, node 23). 
3.5. Multidimensional Results 2. T-Pattern Strategies between Boys and Girls in the Interpersonal Relationships in the Cat and Mouse Roles

Different strategic chains of multidimensional temporal patterns corresponding to mixed interpersonal relationships ( $\mathrm{BG}$ and $\mathrm{GB}$ ) were observed in the $\mathrm{CT}, \mathrm{POH}, \mathrm{MC}$ and $\mathrm{MX}$ sub-roles. The authors identified the most complex T-patterns $(p<0.005)$ and a minimum of 20 events in the cat (MX) and mouse (CT) roles.

\subsubsection{T-Pattern Strategies between Boys and Girls (BG) in the Cat Role (CT)}

Figure 7 shows three strategic chains or temporal regularities of the boys in the cat role. The first chain BG CT SR V LS indicates that, when a boy searched for a girl (BG) in the cat role (CT), they had a light number of relationships (SR), which were of a vigorous (V) and two-step (LS) manner. As a consequence of this first chain, two more were derived. The second BB POH LR M LS and the third strategic chain BB POH LR S LS show that, when a boy switched to the role of pitcher, regularity was associated with looking for another boy (BB), in the role of waiting pitcher (POH), with a low number of relations (LR), and with moderate (M) or sedentary (S) physical effort but in two steps (LS).

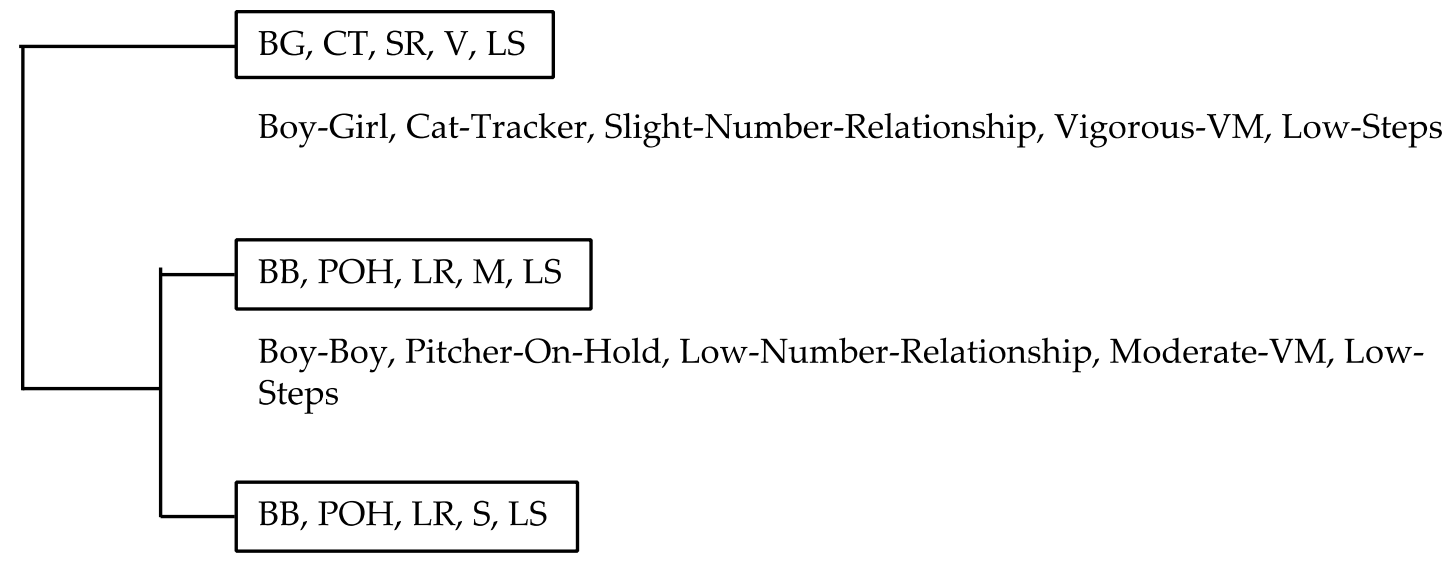

Boy-Boy, Pitcher-On-Hold, Low-Number-Relationship, Sedentary-VM, Low-Steps

Figure 7. Multidimensional Strategic Chains of Mixed Interpersonal Relationships generated by Boys in the Chasing Cat Sub-role.

\subsubsection{T-Pattern Strategies between Girls and Boys (GB) in the Cat Role (CT)}

As for the girls in the cat role (Figure 8), three s-strategic chains or temporal regularities were found. The first temporal pattern (GB CT HR V SS) in the game indicates that when the girl chased the boy (GB) in the cat role (CT), she had a high number of relations trying to catch (HR) vigorously (V) in one step (SS). As a consequence of this regularity, it could happen that, as shown in the second strategic chain GB CT HR V LS, the girl was not very successful in trying to catch the boy with a high number of relations with other participants (GB CT HR V), and stopped chasing them in one step (SS) to continue chasing them in two steps (LS). It could also happen that the girl repeated a temporal pattern or strategic chain, as can be seen in the third strategic chain GB CT HR V SS. 


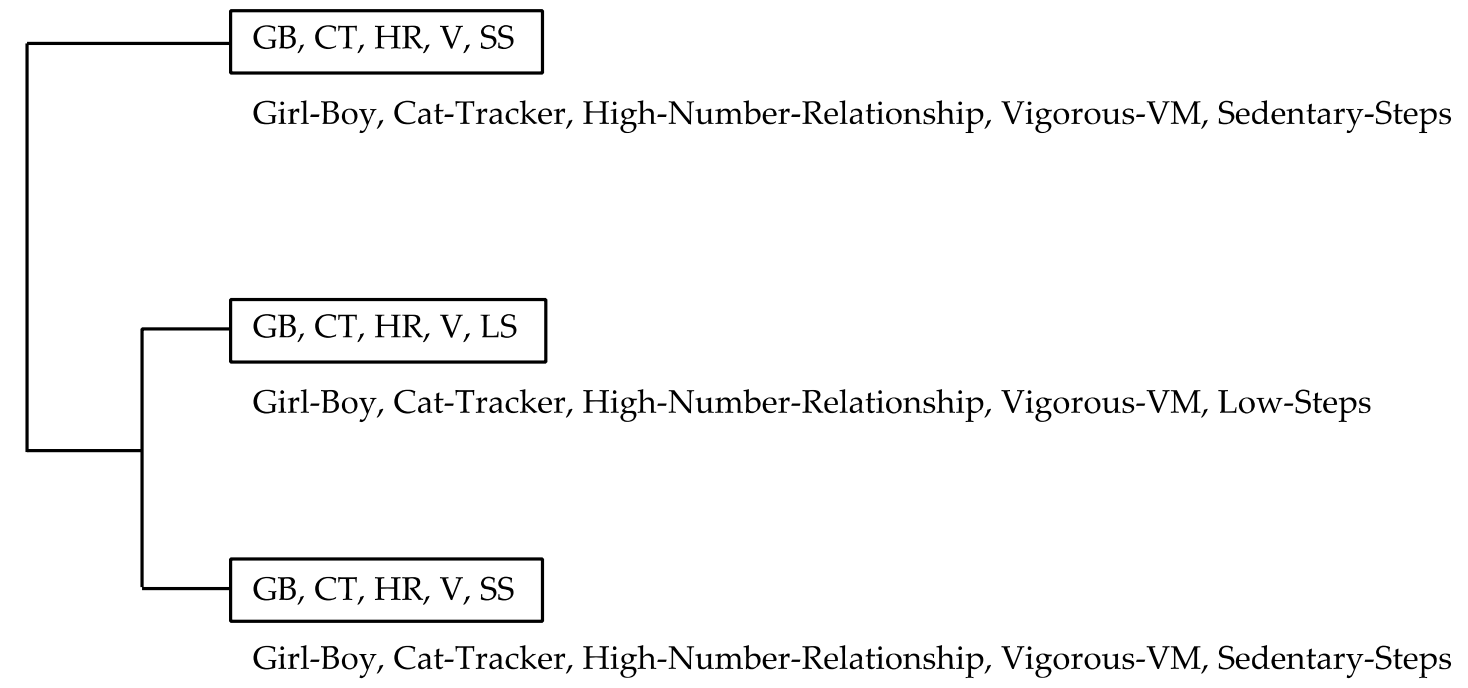

Figure 8. Multidimensional Strategic Chains of Mixed Interpersonal Relationships generated by Girls in the Chasing Cat Sub-role.

3.5.3. T-Pattern Strategies between Boys and Girls (BG) in the Mouse Role (MX)

Figure 9 shows four Multidimensional strategic chains. The first temporal pattern BG MX LR V SS indicates that, when a boy ran away from a girl (BG) in the mouse role (MX), the number of relations was low (LR), although they acted vigorously $(\mathrm{V})$, using one step (SS). From this temporal regularity, a second Multidimensional chain GG POH LR S LS was generated.

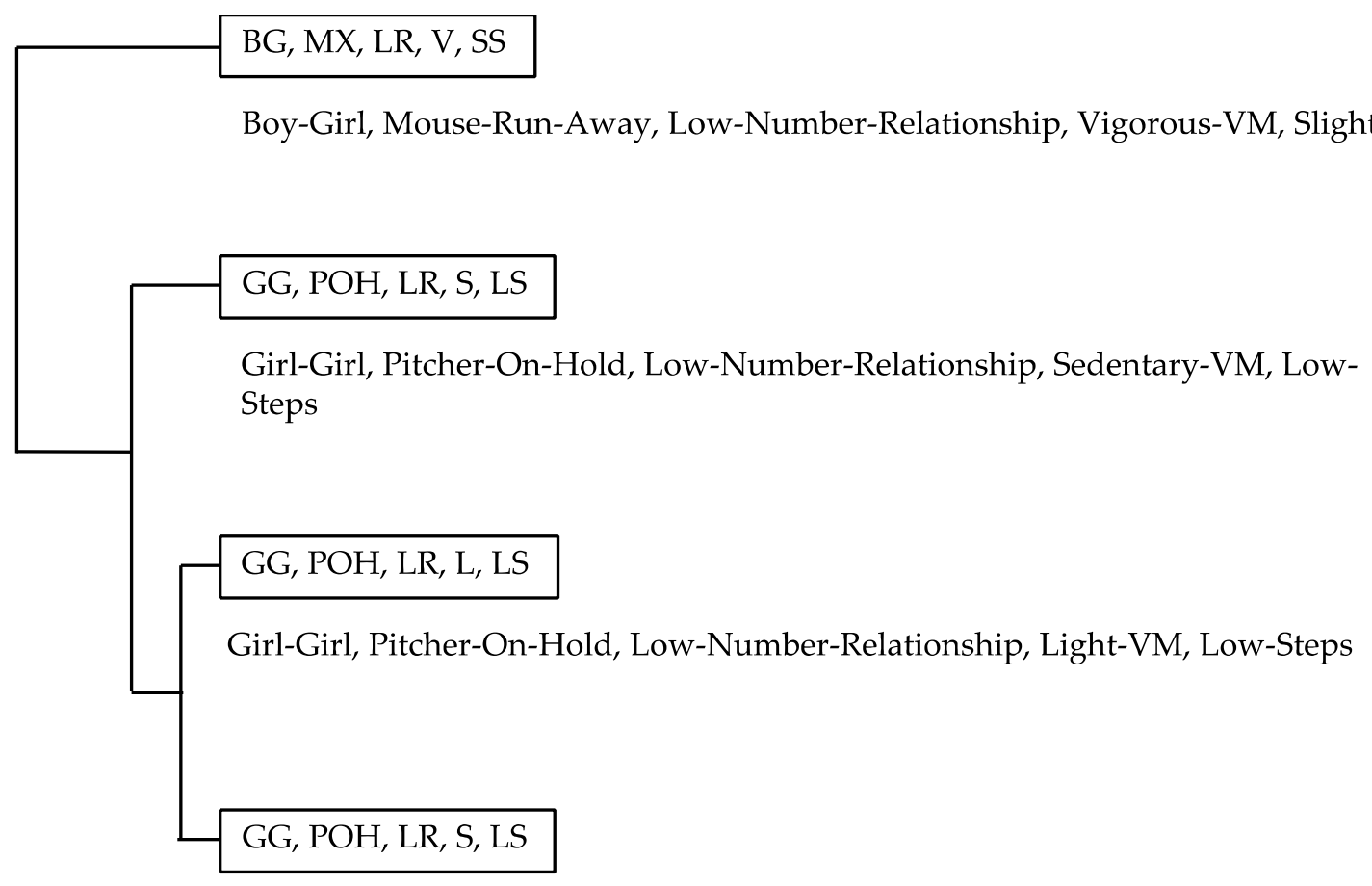

Girl-Girl, Pitcher-On-Hold, Low-Number-Relationship, Light-VM, Low-Steps

Figure 9. Multidimensional Strategic Chains of Mixed Interpersonal Relationships generated by Boys in the Runaway Mouse (MX) Sub-role.

That chain shows that, when girls successfully escaped and switched to the role of pitcher (POH), they joined other girls (GG), staying with the same person in that role, i.e., with a low number of relations (LR), with sedentary effort (S) and with two steps (LS). As a consequence of the second temporal regularity, two more chains were generated. The 
third chain GG POH LR L LS shows that girls could also join other girls (GG) in the role of waiting pitcher $(\mathrm{POH})$, with a low number of relations (LR), but with a light effort level (L) and with two steps (LS) observed. The fourth chain GG POH LR S LS is the same as the second chain, so when the girls tried to join other girls (GG) with a light effort level (L) and it did not work, they went back to what they had tried previously, executing the same behavior pattern, but with a sedentary effort (S).

\subsubsection{T-Pattern Strategies between Girls and Boys (GB) in the Mouse Role (MX)}

In Figure 10, four strategic chains were observed starting from a sequence in which a girl flees as a mouse from a boy who adopts the role of a cat. The first chain GG POH LR L LS indicates that girls searched for girls (GG) when they joined in the cat role (POH), the number of relationships was low (LR) and they acted lightly (L) in two steps (LS). The second chain GG POH LR M LS shows that, when girls joined other girls (GG) in the role of pitcher (POH), they had a low number of relationships (LR), with moderate effort (M) and with two steps (LS). The third string GB MC LR V LS shows that, when a girl ran away from a boy (GB) in the role of mouse (MC), it was associated with a low number of relations (LR), but with a vigorous level of effort (V) and with two steps (LS). The fourth chain GB POH LR L LS shows that, when girls joined other boys (GB) in the role of pitcher (POH), they had a low number of relations (LR), with low effort (L) and with two steps (LS).

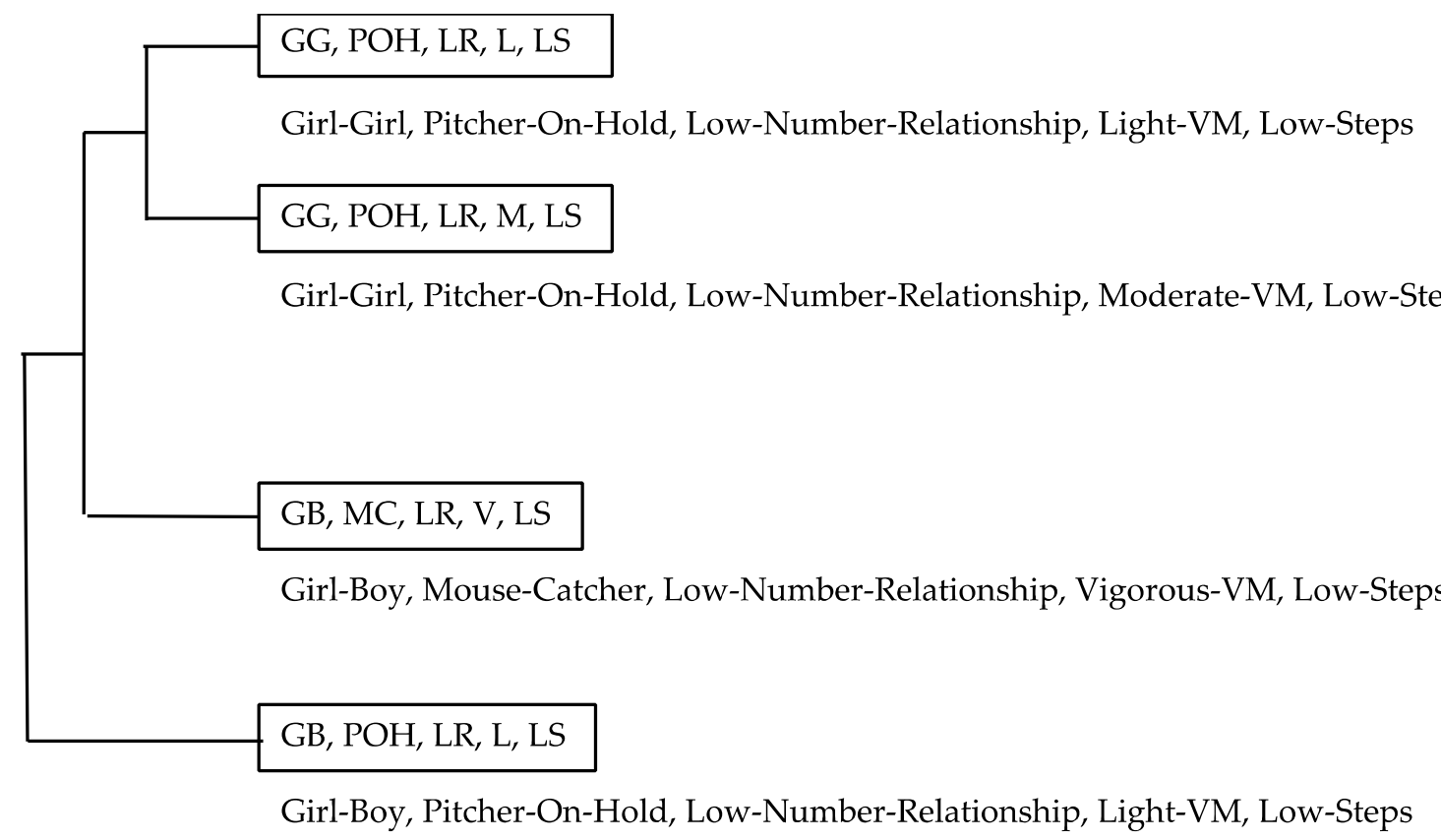

Figure 10. Multidimensional Strategic Chains of Mixed Interpersonal Relationships generated by Girls in the Runaway Mouse (MX) Sub-role.

\section{Discussion}

The first statistical analyzes have enabled us to answer the first objective and to understand the types of relational, decisional and energetic commitments of girls and boys activated by the internal logic of Elbow Tag.

\subsection{The Male, Female, or Mixed Relationships in the Game of Elbow Tag}

The internal logic of the game of Elbow Tag establishes that the socio-motor dynamics [18] of any game are based on a constant transition between the roles of cat, mouse and pitcher. The participants, regardless of their biological characteristics (age, sex, physical condition), must respond to this internal interactive logic by acting under the same conditions. Hence, when a group of players is made up of both genders, the game triggers the successive exchange of relations between boys and girls. The rules state that any boy or girl 
can intervene at any time in one of the three roles. It is therefore not surprising that the first finding of this research confirms that the most predominant relationships are mixed: both boy to girl (BG) and girl to boy (GB). This is a system of general role change (since changing roles involves changing the type of motor relationship with others) and permutation (since when one player changes role, another player takes his or her place) [25].

A detailed analysis of the type of relationship that each gender engages in shows different behaviors.

Boys mainly seek out people of the same gender in relationships in the game (male relationships account for $66.4 \%$ of all interactions). In addition, in the case of the female gender, there is a predominance of mixed relationships $(60.7 \%)$, which are initiated by boys (BG).

In general, masculine interactions $(\mathrm{BB})$ are associated with relating only with another person, whether it be chasing, fleeing, or being in the role of the pitcher. In contrast, in the other possible interactions in which the female gender is present (GG or mixed interactions), the relationship with two people predominates. We interpret this finding as being due to the fact that girls' efficacy in their chase or flight role is lower than that of boys. The relationship between decisional and relational efficacy has also been found in other studies [17].

The rules of the game indicate that the game must be played in pairs and that the change from one role to the other is conditioned by the effectiveness of the cat's decisions in capturing a mouse and the mouse's decisions in escaping from the cat. The players usually succeed in escaping. Hence, the number of people interacted with is mostly two (77.37\%), mainly involving relationships between boys (BB). Relationships with 3 or 4 people played a very small role and interactions with more than 5 people were practically non-existent. In general, this behavior is also maintained among girls and in mixed relationships (BG, GB).

\subsection{Decision-Making According to Interpersonal Relations in the Game of Elbow Tag}

The internal logic of the game of Elbow Tag establishes that each role (cat, mouse and pitcher) requires the participants to make different decisions or sub-roles [24], that is, to solve different problems: for example, the mouse must decide the route, the distance and the speed of their escape, and must also choose the pitcher where they will try to get to safety. The cat, on the other hand, must evaluate how to anticipate the mouse, go very quickly to try to touch the mouse or wait to chase the new mouse that will come out of one of the Elbow Tags; finally, the player who is in a pitcher must decide where to go out, depending on the position and the strategic regularities observed in the cat. Any decision contains a strategic and relational meaning (estimation of action possibilities and choice of a decision, speed, separation distance, type of intervention). Thus, in each game sequence, players establish hypotheses of intervention and estimate possibilities of success according to the unique features observed in their opponents [24].

The rules of the game force the protagonism of the moves to be centered on two roles: cat and Mouse. The rest remain on standby in the role of pitcher. The results show that most of the time (more than $80 \%$ ), the players are in the role of pitcher, adopting the waiting subrole $(\mathrm{POH})$. Despite being a static sub-role, it allows each person to take advantage of these moments to decode the interventions of the two people involved (cognitive involvement). In addition, this intelligent observation also allows one to exchange comments with the partner of the pitcher, whether of the same or of a different gender (relational involvement), and, at the same time, to give oneself up to the emotional contagion that originates the socio-motor or collective dynamics of the others (emotional involvement), bearing witness to the motor empathy that activates this game [24]. All this is transitory since, at any moment, a player may have to abandon the role of the pitcher and flee by adopting the role of the mouse. Despite the predominance of an apparent immobility in the game, in reality, all players are deeply involved in following the outcome of each sequence of the game.

When the players are not in the role of pitcher, they become the cat or the mouse, these being the two roles with a great decisional importance. It was observed that this 
decision-making was similar in male, female, and mixed motor interactions, although with slight particularities. Girls spend more time in the Cat-Tracker sub-role when chasing boys $(8 \%)$. In contrast, this value is halved when the interaction is female when one girl is chasing another $(4 \%)$. The data indicate that girls adopt this sub-role less effectively, i.e., they take the longest time to catch a fleeing mouse. When a boy chases another boy, the time spent in this role is greater (5.54\%) than when boys chase girls (3.85\%). Once again, the effectiveness of this decision-making is responsible for this finding. Thus, it can be stated that the decision-making associated with the cat and mouse roles allows for the exchange of relationships between the two genders. However, differences are evident depending on whether the participants are boys or girls.

In parallel, it is observed that the time spent in the Mouse-Run-Away (MX) role also varies according to the genders involved in the motor interaction. This sub-role is more prominent when a boy runs away from a girl (6.99\%). Most likely, self-confidence to avoid capture leads them to perform longer runs and to look for jugs that are located in other areas of the playing field. On the other hand, when girls run away from boys, the time spent in this sub-role is much shorter $(2.83 \%)$. In order to avoid being caught, the transition to the role of pitcher must be made very quickly so as not to give the mouse time to reach their target. However, this regularity is different when the interaction is between equals, i.e., between people of the same gender. This time is somewhat higher when a girl runs away from another girl (3.26\%) and much higher when the protagonists are boys (5.01\%). In this case, the risk taken is higher, probably because of the certainty that if they change to the role of cat, they will be able to change roles in the short term. The desire to maintain the uncertainty of the confrontation between two people of the same gender, or the preference of girls to end the duel quickly and as soon as possible (when the female gender flees from the male), testifies to the asymmetry observed between the two genders.

\subsection{The Physical Effort in the Function of Interpersonal Relationships in the Elbow Tag Game}

From an organic perspective, the findings confirm once again that the internal logic of Elbow Tag leads players to spend a lot of time in the pitcher role with a minimal intensity of physical effort and a number of steps. When players step out of this role and are the cat or the mouse, variety in energy expenditure is observed. In most of the time away from home, the effort is either vigorous (from $10.2 \%$ to $13.80 \%$ ) or light (from $16.30 \%$ to $19.50 \%$ ). This can be explained by the fact that it is an acyclic game, with sudden accelerations and decelerations; depending on the actions involved in the mouse's flight and its subsequent pursuit by the cat $[40,41]$, these intense efforts of short duration generate an essential energy expenditure, with greater demand on alactic anaerobic metabolism or phosphagen (ATP-CP) [42], and defined by $[43,44]$ as energy power. In this context, vigorous effort reaches the highest values when a girl seeks a boy, i.e., when the challenge is of maximum demand for the female gender. On the other hand, when boys look for girls, vigorous effort reaches the lowest values, probably because the challenge is less demanding from an energetic point of view. Moreover, the interactions between boys are more vigorous than the intensities between girls. This finding confirms the presence of a difference in physical exertion between the two genders. Thus, each game sequence gives rise to challenges with a higher or lower level of agonistic tension, depending on the gender of the protagonists.

\subsection{The Importance of Decision-Making in the Game and Asymmetry in Multidimensional Strategies by Boys and Girls}

The second group of findings responds to the intertwined study of the different variables. The research reveals the predictive power of the different variables in interpreting the decision-making of girls and boys.

The statistical techniques of classification trees and temporal patterns allow us to better understand the intertwined relationship between the different variables. Moreover, they bring us closer to fully understanding the internal dynamics and the regularities that exist in the outcomes of the game. 
When all the variables were put into competition to identify their predictive capacity to explain the different types of social interaction (male, female, or mixed) in the game, a first finding emerges: gender was the main explanatory variable, a fact that reveals differences in the interventions of boys and girls in the game. Boys' interpersonal relationships are mostly masculine (BB), which duplicates the mixed relationships in which girls interact with boys (GB). This behavior is reversed in the case of girls whose female interactions (GG) were half as important as the mixed relationships they receive from boys (BG).

To reveal this web of the social interactions of both genders, the tree hierarchically segments the other variables. The next interpretative variable for boys and girls is the sub-role, i.e., decision-making. The number of people interacted with, and physical effort $(\mathrm{MV})$, are variables with lower predictive power.

The data provided by each variable were the same as those identified by the crosstabulations. However, here they are contextualized with the set of predictor variables. This global look at the relationships between variables shows that the Elbow Tag game has two main actors (the cat and the mouse), with a greater presence and variety of sub-roles in the nodes of the tree. Each game sequence constitutes a strategic Multidimensional unit of decisions that people make when chasing and fleeing. A third role is involved in this set of decisions, which explains the relational complexity of the pitcher game. This is a static role with little energetic involvement, but it will mediate and condition the decision-making associated with the sub-roles in the cat and mouse roles, e.g., in the case of the mouse, to find a refuge from their escape and to choose the person who will replace them, and in the case of the cat, to consider whether to chase the fleeing mouse or to stalk the next mouse to emerge from the role of pitcher.

In this exchange of play sequences, the boys showed a predominance of male interactions (BB) over mixed interactions with girls (GB). This conduct was modified in the sub-roles of mouse fleeing $\mathrm{MX}$ or joining $\mathrm{MJ}$, in which we observe the presence of interactions in which the male mouse flees from the male-female cat (BG). Girls, on the other hand, have a greater number of mixed relationships starting from a boy (BG). Mixed interactions were present in half of the cases. The girls' conduct was also inverted in the sub-roles of mouse fleeing $\mathrm{MX}$ and mouse joining MJ with respect to that of boys, since the majority of cases correspond to the decisions of a girl who, being a mouse, flees from a boy (GB). The same conduct was observed in the physical effort variable by gender.

\subsection{T-Patterns Describe Asymmetric Game Sequences in Girls and Boys When They Perform Multidimensional Strategies}

Finally, the analysis of temporal patterns has provided a response to the third objective.

The intertwined view of the variables becomes more visible when identifying the main temporal patterns of Multidimensional strategic chains in the different roles and the possible asymmetrical situations encountered between genders. Let us turn our attention to the mixed relationships starting from a boy to a girl (BG) or from a boy to a girl (BG) in the cat and mouse roles.

In the cat role, when the boys chase the girls, the chains reveal how successful they are at catching (low number of relations), with vigorous actions and few steps. That Multidimensional chain was followed by two chains in the role of pitcher in the Hold sub-role, with a low number of relations, and with moderate or low effort and few steps. In contrast, the Multidimensional sequences in which a cat girl chases a mouse boy reveal very different participation: girls chasing boys employ a high number of relations; that is, they chase more than four different mice, with vigorous effort and few steps. No chain associated with the role of pitcher was observed, which confirms that in these cases the success of their captures was much lower than that of the boys.

Multidimensional chains in the mouse role also complement the previous findings. In this case, successful sequences are observed for both genders when either boys or girls run away from the Cat. The chain of a boy mouse running away from a girl cat is associated with a low number of relations (meaning he has been able to escape), with vigorous effort and few steps. A boy's success in switching, escaping, and changing roles gives rise to 
another female multidimensional chain (GG) in the Pitcher-On-Hold sub-role, with a low number of relations, and low energetic involvement (physical effort and steps). This first sequence, which is repeated three times, was associated with a role change of cat from the girl chasing mouse, which confirms that in this exchange of motor interactions the girls manage to achieve their goal of capturing and becoming pitchers.

When girls adopt the role of mouse and run away from a boy in the role of cat, the chains show some changes in interpersonal relationships. The first chain corresponds to the female relationship (GG) in the Pitcher-On-Hold sub-role, with a low number of steps and effort. This Multidimensional chain is the result of a successful escape. Next, a girl moves into the pitcher role, where this same frequency is repeated. Subsequently, it is the girl's turn to go out as a mouse-catcher and with vigorous effort and few steps, she manages to escape with few relations, which means that she is not caught and that she manages to change roles. The last chain explains this temporal regularity, with the combination of being in Pitcher-On-Hold, with few relations and little energetic effort (light effort and few steps).

This last analysis allows us to deduce three aspects of interest: (a) the effectiveness of boys in Multidimensional chains in both the cat and the mouse roles; (b) the difficulty of girls in the cat role to quickly capture people who escape; (c) the effectiveness of girls in the mouse role in escaping and moving to the pitcher role, and subsequently in leaving the pitcher role as a pursued mouse and avoiding capture again.

\section{Conclusions}

This study helps us to fully understand the features contained in the internal logic of the game of Elbow Tag and the consequences it triggers in the motor conduct of boys and girls while players were playing through the three roles of cat, mouse, and pitcher. It was confirmed that each role carries unequal scenarios of decisional, relational and energetic interventions, distinguishing the role of pitcher from the roles of cat and mouse.

The different strategies used to analyze the data (contingency tables, classification trees and TPA) complement each other and allow a better understanding of the relationship between the variables. These analyses confirm that the set of variables must be viewed in an intertwined way. This multidimensional view shows that not all variables play an equal role. Social interactions between girls and boys in a mixed group are unequal. This difference is mainly due to decision-making (sub-role variable), which has much greater predictive power than the energetic variables (MV and Steps). "The physical efforts are not the heart of this game, but the relational phenomena that are expressed in an overt or masked way, often to a second degree" [24] (p. 47).

The outcome of the game leads the protagonists to multidimensional sequences in the role changes of cat, mouse, and pitcher associated with different tactical projects. The study has made it possible to capture part of the process or the socio-motor dynamics [24] that the girls and boys were involved in. Unequal temporal regularities were detected according to gender (boy and girl) and roles (cat and mouse). In these roles, boys were more effective than girls, especially in the cat role. In the role of mouse, both genders were successful.

The game of Elbow Tag is characterized by the successive repetition of temporal sequences where momentary failure is relativized by the lack of a final score to record the points scored by the participants. The internal logic of this game allows all participants to enjoy exchanges of different relationships (male, female, and mixed), of decisions (more or less risky, dominant or subordinate to the actions of others), and also of energetic involvement (with different levels of physical effort and steps).

The findings achieved in this research provide a better understanding of the contribution of Traditional Sports Games in quality Physical Education which promotes gender equality $[45,46]$. The governments of Spain and of any country should recognize the educational potential of TSGs. 
This study provides the physical education professional with very valuable evidences to foster physical education based on scientific evidence. It reveals the potential of this game to promote an integral education (organic, relational and decisional) of the students. It also presents evidence of certain asymmetries between the interventions of girls and boys. The equality established by the internal logic of the Elbow Tag gives rise to asymmetrical situations in the strategies used by girls compared to those used by boys.

Once these asymmetries have been verified, the physical education teacher should be attentive to modify the internal logic of the game: for example, by modifying the role-change system to encourage both genders to change roles (from cat to mouse and vice versa). When a player leaves the pitcher he/she becomes a cat, and the previous cat becomes a mouse. In this way, the change occurs very quickly for everyone, allowing girls and boys to modify their motor conducts and therefore their strategies.

All of these findings confirm that the traditional game of Elbow Tag is not a minor game, but is a valuable resource for the physical education teacher.

\section{Limitations and Future Perspective}

A first limitation of this study is the exclusive use of quantitative data to reveal the interventions of the protagonists in the game of Elbow Tag. The implementation of other instruments (self-reports, focus groups, flashback interviews) could provide quality information that helps to interpret the meaning of the girls' and boys' decision-making [47]. Another limitation is not having incorporated other instruments to identify the emotions experienced by the protagonists. Other studies have confirmed the direct relationship between the intensity of positive and negative emotions and the interventions of the participants.

As a future perspective, it is proposed to carry out this study with participants of other age groups and also from other countries. In this way, scientific evidence could be offered to physical education teachers from other cultures where this game is well-known. The authors will also try to design studies considering the use of new instruments and strategies for data analysis $[48,49]$.

Author Contributions: Conceptualization, V.M.-A., P.L.-B. and M.P.; methodology, V.M.-A., M.P., R.L.-P., J.S., C.S.-S., S.D.-S., L.M., R.R.-A., Q.P., C.D.-D. and P.L.-B.; validation, V.M.-A., M.P., R.L.-P., J.S., C.S.-S. and P.L.-B.; formal analysis, P.L.-B. and M.P.; investigation, V.M.-A., M.P., R.L.-P., J.S., C.S.S., S.D.-S., L.M., R.R.-A., Q.P., C.D.-D. and P.L.-B.; data curation, V.M.-A., P.L.-B.; writing-original draft preparation, V.M.-A., P.L.-B.; writing—review and editing, V.M.-A., M.P., R.L.-P., J.S., C.S.-S., S.D.-S., L.M., R.R.-A., Q.P., C.D.-D. and P.L.-B.; visualization, V.M.-A., M.P., R.L.-P., Q.P. and P.L.-B.; supervision, V.M.-A., P.L.-B.; project administration, V.M.-A., P.L.-B. All authors have read and agreed to the published version of the manuscript.

Funding: This research was funded by the Institut Nacional d'Educació Física de Catalunya (INEFC), Universitat de Lleida (UdL), through the 2016 PINEF 00016 project.

Institutional Review Board Statement: The study was conducted according to the guidelines of the Declaration of Helsinki, and approved by the Ethics Committee for Clinical Research of the Catalan Sports Council (protocol code 07/2019/CEICEGC, 3 April 2019)."

Informed Consent Statement: Informed consent was obtained from all subjects involved in the study.

Acknowledgments: This work was supported by the Institut Nacional d'Educació Física de Catalunya (INEFC-UdL) of the Generalitat de Catalunya (Catalonia, Spain).

Conflicts of Interest: The authors declare no conflict of interest.

\section{References}

1. UNICEF. Promoting Gender Equality through UNICEF-Supported Programming in Basic Education; UNICEF: New York, NY, USA, 2011; p. 5.

2. UNESCO. La UNESCO Avanza. La Agenda 2030 para el Desarrollo Sostenible; UNESCO: París, France, $2017 ;$ p. 4.

3. Cárcamo, C.; Moreno, A.; del Barrio, C. Girls Do Not Sweat: The Development of Gender Stereotypes in Physical Education in Primary School. Hum. Arenas 2021, 4, 196-217. [CrossRef] 
4. Kollmayer, M.; Schober, B.; Spiel, C. Gender stereotypes in education: Development, consequences, and interventions. Eur. J. Dev. Psychol. 2016, 15, 361-377. [CrossRef]

5. Metcalfe, S. Adolescent constructions of gendered identities: The role of sport and (physical) education. Sport Educ. Soc. 2018, 23, 681-693. [CrossRef]

6. Preece, S.; Bullingham, R. Gender stereotypes: The impact upon perceived roles and practice of in-service teachers in physical education. Sport Educ. Soc. 2020, 1-13. [CrossRef]

7. Roque, J.I.A.; García, G.G.; Lucas, J.L.Y. Formación emocional y juego en futuros docentes de Educación física. Rev. Electrónica Interuniv. Form. Prof. 2013, 16, 97-108. [CrossRef]

8. Alonso-Roque, J.I.; Lavega-Burgués, P.; Gea, G.M. Incidencia de los juegos de oposición en la vivencia de emociones. In Investigación en el Ámbito Escolar: Un Acercamiento Multidimensional a las Vairables Psicológicas y Educativas; Gázquez, J.J., PérezFuentes, M.C., Molero, M.M., Parra, R., Eds.; GEU: Vitoria-Gasteiz, Spain, 2013; pp. 379-386.

9. Berg, P.; Lahelma, E. Gendering processes in the field of physical education. Gend. Educ. 2010, 22, 31-46. [CrossRef]

10. Gartzia, L.; Galan, A.A.; Lasa, N.B.; Heredia, E.B. Inteligencia emocional y género: Más allá de las diferencias sexuales. Anal. Psicol. 2012, 28, 567-575. [CrossRef]

11. Soler, S. Los procesos de reproducción, resistencia y cambio de las relaciones tradicionales de género en la Educación Física: El caso del fútbol. Cult. Educ. 2009, 21,31-42. [CrossRef]

12. Vidiella, J.; Herraiz, F.; Hernández, F.; Sancho, J.M. Masculinidad hegemónica, deporte y actividad física. Movimiento 2010, 16, 93-115.

13. Sánchez, C.; Chiva, O.; Ruiz, P. Estereotipos de Género y Educación Física en Educación Secundaria; Fundación Dialnet: Logroño, Spain, 2016; p. 11.

14. Soler, S.; Serra, P.; Vilanova, A. La Igualtat en joc: Guia de Bones Pràctiques de GÈNERE en els Estudis de la Família de les Ciències de L'activitat Física i de L'esport (CAFE); INEFC: Barcelona, Spain, 2018.

15. Muñoz-Arroyave, V. Educar la Afectividad a Través de los Juegos Deportivos Tradicionales. Doctoral Dissertation, Universitat de Lleida, Lleida, Spain, 2019.

16. Lagardera, F.; Lavega, P. Introducción a la Praxiología Motriz; Paidotribo: Barcelona, Spain, 2003.

17. Lavega-Burgués, P.; Luchoro-Parrilla, R.A.; Serna, J.; Salas-Santandreu, C.; Aires-Araujo, P.; Rodríguez-Arregi, R.; Mu-ñozArroyave, V.; Ensenyat, A.; Damian-Silva, S.; Machado, L.; et al. Enhancing Multidimensional Learning Through Traditional Sporting Games: Marro360. Front. Psychol. 2020, 11, 1384. [CrossRef] [PubMed]

18. Parlebas, P. Juegos, Deportes y Sociedad. Léxico de Praxiología Motriz; Paidotribo: Barcelona, Spain, 2001.

19. Parlebas, P. Motor praxeology: A new scientific paradigm. In Playing Fields: Power, Practice, and Passion in Sport; Vaczi, M., Ed.; Center for Basque Studies, University of Nevada: Reno, NV, USA, 2013; pp. 127-144.

20. Otegi, J.E.; Del Barrio, S.; Urdangarin, C.; Usabiaga, O.; Oiarbide, A. Ganar, perder o no competir: La construcción temporal de las emociones en los juegos deportivos. Educ. Siglo XXI 2014, 32, 33-48. [CrossRef]

21. Muñoz, V.; Lavega, P.; Serna, J.; de Ocáriz, U.S.; March, J. Estados de ánimo al jugar en solitario o en cooperación: Dos vivencias motrices y afectivas desiguales. Anal. Psicol. 2016, 33, 196. [CrossRef]

22. Muñoz-Arroyave, V.; Lavega-Burgués, P.; Costes, A.; Prat, Q.; Serna, J. University students' affective experiences while playing: A qualitative perspective. Curr. Psychol. 2018, 31, 1-11. [CrossRef]

23. Granja, U.S.D.O.; Burgues, P.L.; Janés, J.M.; Bardavío, J.S. Transformar conflictos motores mediante los juegos cooperativos en Educación Primaria. Univ. Psychol. 2018, 17, 1-13. [CrossRef]

24. Parlebas, P. Jeux traditionnels et dynamique relationnelle. In Sport et Bien-Être Relationnel: Un Autre Aspect de la Santé; Collard, L., Ed.; Chiron: París, France, 2012; pp. 41-85.

25. Parlebas, P. The Universals of Games and Sports. Front. Psychol. 2020, 11, 593877. [CrossRef]

26. Bangsbo, J. Physiology of intermittent exercise. In Exercise and Sport Science; Garrett, W.E., Kirkendall, D.T., Eds.; Lippincott Williams \& Wilkins: Philadelphia, PA, USA, 2000; pp. 53-65.

27. Ato, M.; Lopez-Garcia, J.J.; Benavente, A. Un sistema de clasificación de los diseños de investigación en psicología. Anal. Psicol. 2013, 29, 1038-1059. [CrossRef]

28. Anguera, M.T.; Blanco-Villaseñor, A.; Jonsson, G.K.; Losada, J.L.; Portell, M. Editorial: Best Practice Approaches for Mixed Methods Research in Psychological Science. Front. Psychol. 2020, 11, 590131. [CrossRef]

29. Anguera, M.T.; Blanco, Á.; Hernández, A.; Losada, J.L. Diseños Observacionales: Ajuste y aplicación en psicología del deporte. Cuad. Psicol. Deporte 2011, 11, 63-76.

30. Chacón-Moscoso, S.; Anguera, M.T.; Sanduvete-Chaves, S.; Losada, J.L.; Lozano, J.A.L.; Portell, M. Methodological quality checklist for studies based on observational methodology (MQCOM). Psicothema 2019, 31, 458-464.

31. Parlebas, P. A pedagogy of motor skills. Acción Mot. 2017, 20, 89-95.

32. Navarro-Adelantado, V.; Pic, M. Gamesplay Clues for Motor Interactons in a Triad Game. Rev. Int. Med. Cienc. Ac. 2021, 21, 355-374. [CrossRef]

33. Casarrubea, M. Possible Contribution of T-pattern Detection and Analysis to the Study of the Behavioral Correlates of Afferent Inhibition. Brain Sci. 2020, 10, 818. [CrossRef] [PubMed] 
34. Gomez, M.-. Ángel; Rivas, F.; Connor, J.D.; Leicht, A.S. Performance Differences of Temporal Parameters and Point Outcome between Elite Men's and Women's Badminton Players According to Match-Related Contexts. Int. J. Environ. Res. Public Health 2019, 16, 4057. [CrossRef] [PubMed]

35. Cohen, J. Statistical Power Analysis for the Behavioural Sciences, 2nd ed.; Erbaum Press: Hillsdale, NJ, USA, 1988.

36. Casarrubea, M.; Davies, C.; Pierucci, M.; Colangeli, R.; Deidda, G.; Santangelo, A.; Aiello, S.; Crescimanno, G.; Di Giovanni, G. The impact of chronic daily nicotine exposure and its overnight withdrawal on the structure of anxiety-related behaviors in rats: Role of the lateral habenula. Prog. Neuro Psychopharmacol. Biol. Psychiatry 2021, 105, 110131. [CrossRef]

37. Pic, M.; Jonsson, G.K. Professional boxing analysis with T-Patterns. Physiol. Behav. 2021, 232, 113329. [CrossRef] [PubMed]

38. Magnusson, M.S. Discovering hidden time patterns in behavior: T-patterns and their detection. Behav. Res. Methods Instrum. Comput. 2000, 32, 93-110. [CrossRef]

39. Pic, M.; Navarro-Adelantado, V.; Jonsson, G.K. Exploring playful asymmetries for gender-related decision-making through T-pattern analysis. Physiol. Behav. 2021, 236, 113421. [CrossRef]

40. Barrera, F.A.; Gracia, Á.J. Revista Digital: Actividad Física y Deporte Medio de Comunicación de los Profesionales y Estudiantes de la Actividad Física y el Deporte; Universidad de Ciencias Aplicadas y Ambientales: Bogotá, Colombia, 2016; Available online: https: / / repository.udca.edu.co/handle/11158/3063\#.YC-HZBi1jS8.mendeley (accessed on 1 March 2021).

41. Casas, A. Physiology and methodology of intermittent resistance training for acyclic sports. J. Hum. Sport Exerc. 2008, 3, 23-52. [CrossRef]

42. Fox, E.L.; Mathews, D.K. Conditioning for sports and general fitness. In Exercise Physiology: Theory Application to Fitness and Performance, 5th ed.; McGraw-Hill: Boston, MA, USA, 2004.

43. Dal Monte, A. La Valutazione Funzionale Dell'atleta; Sansoni: Firenze, Italy, 1983.

44. Dal Monte, A.; Gallozi, C.; Lupo, S.; Marco, E.; Menchinelli, D. Evaluación funcional del jugador de baloncesto y balonmano. Apunts 1987, 24, 243-252.

45. Colomer, J.; Serra, T.; Cañabate, D.; Bubnys, R. Reflective Learning in Higher Education: Active Methodologies for Transformative Practices. Sustainability 2020, 12, 3827. [CrossRef]

46. Trigueros, R.; Sanchez-Sanchez, E.; Mercader, I.; Aguilar-Parra, J.M.; López-Liria, R.; Morales-Gázquez, M.J.; Fernández-Campoy, J.M.; Rocamora, P. Relationship between Emotional Intelligence, Social Skills and Peer Harassment. A Study with High School Students. Int. J. Environ. Res. Public Health 2020, 17, 4208. [CrossRef]

47. Govorova, E.; Benítez, I.; Muñiz, J. Predicting Student Well-Being: Network Analysis Based on PISA 2018. Int. J. Environ. Res. Public Health 2020, 17, 4014. [CrossRef] [PubMed]

48. Bernal-García, M.I.; Jiménez, D.R.S.; Gutiérrez, N.P.; Mesa, M.P.Q. Validez de contenido por juicio de expertos de un instrumento para medir percepciones físico-emocionales en la práctica de disección anatòmica. Educ. Méd. 2020, 21, 349-356. [CrossRef]

49. Santoyo, C.; Jonsson, G.K.; Anguera, M.T.; Portell, M.; Allegro, A.; Colmenares, L.; Torres, G.Y. T-patterns integration strategy in a longitudinal study: A multiple case analysis. Physiol. Behav. 2020, 222, 112904. [CrossRef] [PubMed] 